\title{
Density Pervades: An Analysis of Phonological Neighborhood Density Effects in Aphasic Speakers with Different Types of Naming Impairment
}

\author{
Erica L. Middleton and Myrna F. Schwartz \\ Moss Rehabilitation Research Institute
}

\section{Abstract}

We investigated the influence of phonological neighborhood density (PND) on the performance of aphasic speakers whose naming impairments differentially implicate phonological or semantic stages of lexical access. A word comes from a dense phonological neighborhood if many words sound like it. Limited evidence suggests that higher density facilitates naming in aphasic speakers, as it does in healthy speakers. Using well controlled stimuli, Experiment 1 confirmed the influence of PND on accuracy and phonological error rates in two aphasic speakers with phonological processing deficits. In Experiments 2 and 3, we extended the investigation to an aphasic speaker who is prone to semantic errors, indicating a semantic deficit and/or a deficit in the mapping from semantics to words. This individual had higher accuracy, and fewer semantic errors, in naming targets from high versus low density neighborhoods. It is argued that the results provide strong support for interactive approaches to lexical access, where reverberatory feedback between wordand phoneme-level lexical representations not only facilitates phonological level processes but also privileges the selection of a target word over its semantic competitors.

\section{Keywords}

phonology; neighborhood density; aphasia; interactivity; lexical access

The study of errors in speech has long informed the understanding of the processes underlying speech production. Early analyses of speech error corpora (Fromkin, 1971; Garrett, 1975; 1982) strongly informed the formulation of the prevailing theoretical framework of sentence production. In this framework, a communicative intention initiates a stage dedicated to semantic/syntactic encoding (i.e., selection of words and construction of a hierarchically-organized syntactic frame) followed by linearization of sentence elements and realization of their phonological forms. In work on single word production or lexical access, theorists have largely adopted this framework, though debates surround whether the stages are strictly serial and whether later levels of encoding can affect prior levels of encoding or interact (for relevant debates see Butterworth, 1989; Dell, 1986; Dell \& Reich, 1981; Dell \& O’Seaghda, 1992; Foygel \& Dell, 2000; Harley, 1993a, 1993b; Levelt, Roelofs, \& Meyer, 1999; Levelt et al., 1991; Peterson \& Savoy, 1998; Roelofs, 1992, 1997; Ruml, Caramazza, Capasso \& Miceli, 2005; Schriefers, Meyer, \& Levelt, 1990; Stemberger, 1985; Rapp \& Goldrick, 2000; Vigliocco \& Hartsuiker, 2002). These issues aside, the general framework of single word production involving two stages is largely accepted today. The first stage is dedicated to the selection of an abstract non-phonological word node (or lemma; Kempen \& Huijbers, 1983; Levelt, 1989; cf., Caramazza, 1997 for a different view) that captures a

Please address correspondence to: Erica Middleton, Moss Rehabilitation Research Institute, 60 Township Line Rd., Elkins Park, PA, 19027, United States, Phone: (215) 663-6967, Fax: (215) 663-6783, middleer@einstein.edu. 
speaker's meaning (hereafter, word selection). The second stage is dedicated to retrieval of a word's constituent phonemes (hereafter, phonological retrieval). A lemma is thought to be responsible for specifying, minimally, semantic conditions for a word's use, its class (e.g., noun, verb, adjective), required syntactic arguments (relevant in the context of phrasal or sentence level constructions) and grammatical features such as gender and number. In addition to evidence derived from speech error-corpora, support for the two-stage view of lexical access comes from analyses of the time course of semantic and phonological activation (Schriefers et al., 1990; Levelt et al., 1991) as well as investigations of wordfinding failures in normal (Vigliocco, Antonini, \& Garrett, 1997) and aphasic speech (Badecker, Miozzo, \& Zanuttini, 1995).

Efforts to understand lexical access include the development of computational models that incorporate the two-stage framework (Dell, 1986; Dell, Schwartz, Martin, Saffran \& Gagnon, 1997; Dell, Martin, \& Schwartz, 2007; Foygel \& Dell, 2000; Harley, 1993b; Schwartz, Dell, Martin, Gahl, \& Sobel, 2006; Levelt et al., 1999; Rapp \& Goldrick, 2000; Roelofs, 1992, 1997; Ruml et al., 2005). Dell, Schwartz and colleagues applied the interactive two-step model of lexical retrieval (adapted from Dell, 1986) to error data from both healthy speakers as well as large groups of individuals with types of aphasia spanning all the classic syndromes (Dell et al., 1997; Foygel \& Dell, 2000; Schwartz et al., 2006). A major strength of this work is the ability to explain patterns of errors produced by both normal and aphasic speakers using the same basic model architecture, an endeavor consistent with the continuity hypothesis (see Dell et al., 1997; Ruml et al., 2005; Schwartz et al., 2006 for discussion). Tenets of the continuity hypothesis are that the same basic mechanisms underlie both errorful and errorless speech in aphasic and normal speakers, respectively. An implication is that language breakdown in aphasia is principled in its relation to the cognitive architecture underlying normal and pathological language use.

In the spirit of the continuity hypothesis, the present work explores the influence of phonological neighborhood density (PND) on aphasic speech, a factor which has been shown to impact language processing in nonaphasic speakers. We evaluate predictions relevant to interactive accounts of lexical access (Dell, 1986; Dell et al., 1997; Dell \& Gordon, 2003; Foygel \& Dell, 2000; Harley, 1993b; Schwartz et al., 2006; Stemberger, 1985; see Rapp and Goldrick, 2000; Vigliocco and Hartsuiker, 2002 for reviews). In these approaches, word selection (an earlier process) is influenced by phonological retrieval and encoding (later processes) by virtue of activation spreading iteratively between word representations and phonological representations before word selection is complete. Such approaches contrast with views where there is no feedback between the stages of encoding (i.e., feedforward views; Butterworth, 1989; Levelt et al., 1999; Roelofs, 1992, 1997). The present work uses PND effects in the performance of aphasic speakers to diagnose the workings of interactivity, thus serving as an evaluation of interactive approaches to lexical access.

\section{Phonological Neighborhood Density Effects in Normal Speakers}

Essentially, a word comes from a phonologically dense neighborhood if many words sound like it. A commonly used rule for identifying neighbors is any word that can be made into a target word by the addition, deletion, or substitution of a single phoneme (Best, 1995; Luce \& Pisoni, 1998; Vitevitch \& Luce, 1998, 1999; Vitevitch \& Sommers, 2003; Vitevitch, 2002). With respect to input processing of words, PND slows recognition as seen in slower reaction times to words from high density rather than low density neighborhoods in auditory naming tasks and auditory lexical decision (Luce and Pisoni, 1998; Vitevitch \& Luce, 1998; 1999). The conclusion is that recognition is inherently competitive, and the more similar sounding words there are to a target, the more difficult it is to discriminate. On the output 
side, however, greater PND is facilitative. Across a number of experiments Vitevitch (2002) and Vitevitch and Sommers (2003) have found in picture naming that words from high density neighborhoods are produced faster than words from low density neighborhoods (see also Baus, Costa, and Carreiras, 2008 for similar findings in Spanish).

PND also appears to promote errorless speech (Burke, MacKay, Worthley, \& Wade, 1991; German \& Newman, 2004; Harley \& Bown, 1998; James \& Burke, 2000; Meyer \& Bock, 1992; Vitevitch, 1997, 2002; Vitevitch \& Sommers, 2003; cf., Newman \& German, 2002, 2005 , for different results). Based on an analysis of natural error corpora compiled by Fay and Cutler (1977), Vitevitch (1997) found words that were prone to malapropism errors (replacement by a similar sounding word) were lower in density than a random sample of words matched in length and syntactic class. Vitevitch (2002; Experiment 1) found that initial phoneme exchanges in a SLIP procedure (spoonerisms of laboratory induced predisposition technique; Baars, Motley, \& MacKay, 1975) were more likely for word pairs from low density neighborhoods than high. Low density words are associated with more errors in tongue-twister production (Vitevitch, 2002; Experiment 2) and are more prone to tip-of-the-tongue states in healthy adult speakers (Burke, MacKay, Worthley, \& Wade, 1991; Harley \& Bown, 1998; James \& Burke, 2000; Meyer \& Bock, 1992; Vitevitch \& Sommers, 2003; see German \& Newman, 2004 for similar results with children). Important to note, Vitevitch (2002) found that PND effects are not reducible to phoneme frequency (i.e., the position-specific frequency of phonemes and sequences of phonemes in a syllable) because PND effects persist when these factors are controlled. Rather, PND effects reflect the influence of lexical neighbors on phonological encoding.

\section{Interactivity and Phonological Neighborhood Density in Lexical Access}

What is the mechanism through which words that are phonologically related to a target facilitate its production? In an effort to understand this relationship, Dell and Gordon (2003) modeled PND effects within the interactive two-step framework. The model consists of an initial input layer of units corresponding to semantic features of words, a middle layer corresponding to unitary non-phonological word nodes (lemma layer), and an output layer comprising units corresponding to individual phonological segments (see Figure 1). All links between the levels are bi-directional, and lexical access proceeds in two overlapping stages dedicated to the mapping from semantics to a word node (word selection) followed by access of the word's phonological segments (phonological retrieval). Word selection begins with a jolt of activation to the semantic features of the target (e.g., CAT). Over a number of time steps, this activation spreads through weighted links to the target word as well as nontarget words that share semantic features with the target (e.g., DOG). Activation also cascades to and reverberates back from the phonemes of activated words, heightening the activation of not only the target but phonologically-related words as well (e.g., MAT, FAT). This is demonstrative of the cascading and interactive properties of the model -phonemes of the target are activated before word selection is complete, and bi-directional links feed activation back from phonology to the word level to influence activation patterns there. Word selection concludes after a fixed number of time steps: the most highly activated word is tagged and receives a direct jolt of activation, thus activating its phonological segments. Output is a set of phonemes specified for their position in the syllable.

An important feature of the interactive two-step model (Dell, 1986; Dell et al., 1997; Dell \& Gordon, 2003; Foygel \& Dell, 2000; Schwartz et al., 2006) is its ability to make the types of errors found in the speech of healthy adults as well as aphasic speakers when producing single words. Examples of some of the error types modeled include semantic errors (e.g., DOG for CAT), mixed errors which are both semantically and phonologically related to the target (e.g., RAT for CAT), formal errors (phonologically-related word outcomes such as 
MAT for CAT) and phonologically-related nonword errors (e.g., DAT). Errors in the model are made possible via two main mechanisms: (1) inclusion of a noisy activation rule where activation levels at each timestep are perturbed by normally distributed noise; (2) manipulation of parameters that control the spread of activation (e.g., connection weight; decay rate) away from the default (normal) value. The second mechanism is termed 'lesioning' and is used to create models that simulate aphasic naming performance. Errors arise when activation for non-target nodes exceed the activation level of target nodes (either words or phonemes) at the moment of retrieval.

In the two-step interactive theory, different error types arise at each of the two steps of lexical access. Semantic errors arise during word selection when a semantically-related word, activated by input from features shared with the target, is selected in place of the target. Mixed errors also arise during word selection, the result of feature sharing and feedback from shared phonemes. Formal errors exhibit a dual nature in that they may arise either during word selection due to feedback from shared phonemes with the target, or from an error in phonological retrieval that coincidentally results in a word. Nonwords result from errors during phonological retrieval.

It is important to note that the interactive two-step theory does not address errors that arise outside of the two stages dedicated to selection of a word and retrieval of its constituent phonemes. The model assumes that semantic errors in naming are invariably due to selection of the wrong word given the correct semantic input. However, in cases where semantic errors in naming occur alongside semantic errors in comprehension, it is reasonable to suspect that something is amiss within semantics itself, i.e., in the integrity of semantic representations or the executive systems that control them (Gainotti, Miceli, Caltagirone, Silveri, \& Masullo, 1981; Hart \& Gordon, 1990; Hillis, Rapp, Romani, \& Caramazza, 1990; Jefferies \& Lambon Ralph, 2006). Similarly, the model assumes that all phonological naming errors are lexically generated, the product of faulty phoneme retrieval (Schwartz, Wilshire, Gagnon, \& Polansky, 2004), whereas there is evidence to suggest that such errors can also arise post-lexically, during phonemic buffering/sequencing, and/or phonetic/ articulatory operations (Goldrick \& Rapp, 2007; Romani \& Galluzzi, 2005; Shallice, Rumiati, \& Zadini, 2000). We will consider these issues further in connection with the characterization of our study participants.

Dell and Gordon (2003) explored PND effects within the interactive two-step model by comparing accuracy and error patterns in versions of the model with high versus low density neighborhoods. For example, the lexicon of the high density model included-for the target CAT - the phonologically-related neighbors HAT and MAT as well as semantically-related and unrelated items such as DOG, LOG and FOG. The low density model was created by eliminating one of the two phonologically-related neighbors. Performance was also compared to an "empty" model, which contained no phonologically-related neighbors to the target. Dell and Gordon examined PND effects in both a "normal" (unlesioned) model architecture as well as in lesioned models. Performance was evaluated by having the models attempt to produce the target CAT thousands of times, and evaluating each trial for accuracy and type of error produced. The patterns were consistent across the normal model and the model lesioned by decay rate of activation - accuracy in word selection and phonological retrieval increased with increasing density. Thus, errors that the model associates with word selection (e.g., semantic errors, mixed errors), as well as errors that it associates with phonological retrieval (e.g., phonologically-related nonword errors) both decreased with increasing density.

As described earlier, healthy speakers produce fewer phonological errors with increasing density (Vitevitch, 2002). Facilitation in phonological retrieval from phonologically-related 
neighbors has been interpreted as evidence for interactivity (Goldrick, Folk, \& Rapp, 2010; Vitevitch, 2002). In the framework of Dell and Gordon (2003), the incipient activation of the target phonemes feeds back to the target and its phonological (word) neighbors, creating feedback loops (Dell, 1986). Higher density means that more neighbors are involved in these feedback loops. Though more neighbors also means that more irrelevant phonemes (phonemes not shared with the target) will become activated during phonological retrieval, this disadvantage is overridden by the facilitative impact from having more neighbors sending converging activation to a target's phonemes when a target hails from a high (versus low) density neighborhood. Experiment 1 investigates the influence of PND on naming error rates in two speakers with phonological level deficits.

The Dell and Gordon model also predicts effects at the word selection stage. This is because the feedback loops between phonemes and the words that instantiate them come into effect early (a consequence of activation cascading from the target word to its constituent phonemes). Because naming is a semantically-driven task, the major competitors to the target at word selection are words that are similar to it in meaning. These competitors receive little if any benefit from the phonological feedback loops, unlike the target. Thus, higher density heightens the target's activation relative to the semantically-related words that are its natural competitors at this level. Experiments 2 and 3 test this model prediction.

The modeling work of Dell and Gordon (2003) provides an explicit account of how phonological neighbors exert their influence via interactivity to bolster word selection and phonological retrieval during lexical access. Important to note, the reported PND effects on word selection and phonological processes would be consistent with any view of lexical access which invokes sufficient interactivity between phonological and word-level encoding. In contrast, such effects would be inconsistent with feedforward models of lexical access, which do not postulate interactivity from phonological representations to word level representations (Butterworth, 1989; Levelt et al., 1999; Roelefs, 1992, 1997).

\section{Phonological Neighborhood Density Effects on Word Production in Aphasia}

Akin to the work with healthy speakers, evidence suggests that greater PND facilitates naming in speakers with aphasia (Best, 1995; Goldrick et al., 2010; Gordon \& Dell, 2001; Gordon, 2002; Kittredge, Dell, Verkuilen, \& Schwartz, 2008). Controlling for syllable length, Best (1995) reported an increase in accuracy with words from high compared to low density neighborhoods for her patient, CGJ, who otherwise demonstrated a reverse length effect (i.e., better performance on longer words, though presumably not because they have fewer neighbors). Gordon (2002) analyzed the relationship between PND and phonological error frequency in the speech of a large, undifferentiated group of patients with aphasia. In regression analyses applied to picture naming data, Gordon found word frequency and PND (which were moderately correlated) independently contributed to the incidence of phonological errors after syllable length had been taken into account. Similar to Gordon (2002), Kittredge et al. (2008) reported effects of PND on semantic and phonological errors in a large undifferentiated population of aphasics in multiple regression analyses which included the variables of imageability, age-of-acquisition, lexical frequency, name agreement and number of phonemes. One of the goals of the present work is to clarify the scope of PND influences during word production. We do this by analyzing PND effects in the naming performance of aphasic speakers who demonstrate impairments specific to different stages of the naming process.

Goldrick et al., (2010) used Monte Carlo simulations to identify a number of lexical and form-based factors that exert (at least partially) independent effects in the production of 
formal (word) error outcomes in spoken and written aphasic performance. These factors included position-specific segmental overlap, frequency, grammatical category, number of segments, and (for one patient) syllable length. From these results they derived a definition of neighborhood which combines lexical and form-based factors (termed Lex-Form) that are relevant to the activation of formal neighbors. To evaluate the functional significance of Lex-Form, they conducted a posthoc analysis, drawing high density words (i.e., defined as having two or more "strong" neighbors that were similar to the word in form, were of higher frequency, and of same grammatical category) and low density words (i.e., no strong neighbors) from the total data set for each patient. Word accuracy was higher on the high density words compared to the low density words. Though this analysis demonstrates that their multi-factored definition of neighborhood (Lex-Form) is relevant to accuracy in spoken and written naming in aphasia, it does not establish which of the factors that compose LexForm individually impact accuracy. As our focus is to evaluate predictions of the Dell and Gordon (2003) model, whose key claims have to do with the number of phonologicallyrelated neighbors, in the present work we investigate the influence of PND (defined in terms of number of neighbors) on naming performance in aphasia while holding the factors that compose Goldrick et al.'s Lex-Form constant. We also control for a number of variables they did not investigate, including phonotactic probability, as explained below.

The current project seeks to build on prior work by investigating the influence of PND on the naming performance of speakers with aphasia while accounting for a greater range of extraneous variables than has been investigated before (see Tables 3, 5, and 7 for variables investigated in the current experiments). The materials for each experiment were constructed with the goal of equating high and low density words, in an a priori fashion, for the majority of variables listed in Tables 3,5, and 7 . When this was not possible, the remaining variables were dealt with statistically in regression analyses. Among others, a key variable accounted for in the current work that had not been dealt with in prior investigations of PND effects in aphasia is phonotactic probability (i.e., position-specific phoneme frequency and the frequency of particular phoneme sequences). It is reasonable to assume this variable could be a confound in prior work on PND effects in aphasia because with increasing numbers of phonologically-related neighbors, the frequency of shared phonemes and sequences of shared phonemes should increase as well. In the present experiments, phonotactic probability was one of several factors controlled in an a priori fashion.

Using such controlled materials, our main goal was to investigate the level(s) of lexical access that are impacted by the density of phonological neighbors. The interactive model of Dell and Gordon (2003) predicts that PND influences the word-selection stage as well as phonological retrieval. To test this, we investigated PND effects in aphasic individuals whose deficits impacted different stages of the naming process. Experiment 1 investigated PND effects in two aphasic speakers (P1 and P2) who, in a naming evaluation, produced a predominance of phonological errors (e.g., phonological nonwords). Experiments 2 and 3 investigated the influence of PND on the naming performance of a third aphasic speaker (P3) who showed minimal phonological disturbance. Instead, the naming evaluation demonstrated that she was prone to semantic errors. Experiment 2 used largely the same materials as in Experiment 1 but with small changes to exert tighter experimental control over numerous lexical and sublexical variables, as reported in Tables 3, 5, and 7. Experiment 3 extended the investigation of PND effects on P3's naming performance to a new set of controlled materials.

To anticipate, we found that higher PND was associated with fewer phonological errors in $\mathrm{P} 1$ and $\mathrm{P} 2$ and with fewer semantic errors in P3. The tight control over confounding variables in this study lends confidence that facilitative effects of PND truly derive from the influence of activated phonological neighbors during the semantic and phonological stages 
of naming, and not to confounding effects of other variables known to influence lexicalsemantic encoding (e.g., target familiarity) or post-lexical phonological encoding (e.g., phonotactic probability). On this basis, we argue that the results provide strong support for interactive accounts of naming, which offer a natural explanation for how phonological neighbors become activated during a semantically-driven task like naming, and why this should reduce the probability of phonological and semantic errors.

\section{Experiment 1}

Experiment 1 investigated the effect of PND on the naming of two individuals with aphasia who were prone to phonological errors in naming.

\section{Methods}

Participants-Two individuals with chronic, post-stroke aphasia were recruited from the Moss Rehabilitation Research Institute's pool of research volunteers based on test scores indicating a phonological output deficit. They gave informed consent under a protocol approved the Institutional Review Board of Albert Einstein Healthcare Network of Philadelphia, PA. and were reimbursed $\$ 15$ for each hour of participation. They also consented to undergo a structural MRI or CT imaging to localize their lesion(s). Imaging was conducted at the University of Pennsylvania School of Medicine under their IRB protocol.

P1: P1 was a 74-y.o. right handed male who had 21 years of education and was employed as a scientist prior to sustaining a stroke 21 months earlier. A structural MRI revealed a discrete left temporo-parietal lesion, involving Brodmann areas 39 and posterior 22. On the Western Aphasia Battery (WAB; Kertesz, 1982), he obtained an Aphasia Quotient of 56 and was classified as having Conduction Aphasia. This is based on a profile of fluent spontaneous speech (fluency score $=5$ ), good auditory comprehension $(79 \%)$ and relatively poor repetition $(50 \%)$. A clinical screen for speech apraxia (Dabul, 2000) was negative.

Table 1 shows P1's performance on additional measures of repetition (word and nonword repetition tests), word comprehension (picture-word verification test: does the word match the picture?; synonym triplets: pick two of three words that are synonyms) and picture comprehension (Camel and Cactus Test, picture version: Does camel go best with cactus, tree, sunflower, rose?; Bozeat, Lambon-Ralph, Patterson, Garrard, \& Hodges, 2000). The reported z-scores are calculated from the mean and standard deviation of a large diverse group of patients with aphasia resulting from left-hemisphere stroke $(\mathrm{N}=86$ for the $C C T$, picture-word verification test, and synonym selection task; $\mathrm{N}=84$ for word and nonword repetition). Table 2 shows P1's performance on the Philadelphia Naming Test (Roach, Schwartz, Martin, Grewal, \& Brecher, 1996). One can see from these tables that P1 performed above the aphasia mean on the tests of word and picture comprehension but at the mean on word and nonword repetition. A phonological impairment was most apparent in his performance on the PNT, where phonologically related nonwords and formal errors were in abundance compared to semantic errors.

On some accounts, phonological errors can originate at production stages peripheral to lexical-phonological access, and this is particularly likely in patients with a phonetic/ articulatory impairment. As noted earlier, P1 did not qualify as having clinically evident speech apraxia. As a further check, we coded his word repetition responses from the Philadelphia Repetition Test (PRT; Dell et al., 2007) for phonetic errors (see Romani \& Galluzzi, 2005 for details). In this analysis, a naïve coder and the first author independently coded correct repetitions for distortions in how phonemes were produced. The coders considered a word to contain a phonetic error if the phoneme was slurred or produced with 
an audible effort. The raters agreed on $100 \%$ of their judgments. P1 produced no phonetic errors, bolstering the evidence his phonological naming errors did not arise at phonetic/ articulatory levels.

Further analysis of P1's repetition errors revealed that they were predominantly substitution errors of individual phonemes, consonant clusters or whole syllables. Among his repetition errors, he produced only two possible contextual errors (out of 20). Contextual errors, which include anticipations, perseverations, or exchanges of phonemes elsewhere in the word have been interpreted as indicative of a disrupted post-lexical sequencing stage (Buckingham, 1986; Kohn \& Smith, 1990) that operates after phonemes are retrieved. However, it is not necessary to invoke separate post-lexical processes to explain contextual errors as they arise in the Dell family of naming models as errors in the timing with which phonemes are retrieved (see Dell, 1986 for discussion). Nevertheless, as P1 shows no evidence of phonetic/articulatory impairment, and almost all of his repetition errors do not appear to be errors in the sequencing of retrieved phonemes, P1 may be said to have primarily a deficit in phonological retrieval (step-2 in the two-step interactive theory of lexical access).

P2: P2 was a 53-y.o. right-handed male with 12 years of education who was employed as a truck driver before suffering a stroke 21 months before time of test. P2's performance on the WAB revealed a classification of Conduction Aphasia based on a profile of fluent spontaneous speech (fluency score $=6$ ), good auditory comprehension $(71 \%)$ and relatively poor repetition (60\%). Structural MRI revealed a classic conduction aphasic lesion profile, with a significant amount of damage to Brodmann areas 39 and 40 extending anteriorly to involve the insula and underlying white matter including the arcuate fasciculus. The clinical screen for speech apraxia (Dabul, 2000) revealed P2 to be mildly apraxic. P2 showed average or above average performance (compared to the aphasia mean) on tests of word and picture comprehension, but his performance on tests of word and nonword repetition were below average (Table 1). His errors on the PNT were predominantly phonological (e.g., phonologically-related nonwords and formal errors; Table 2).

A naïve coder and the first author independently coded correct repetitions on the Philadelphia Repetition Test for phonetic distortions using the same criteria described above. The raters independently agreed on $92 \%$ of their judgments, and disagreements were resolved through discussion. Commensurate with the diagnosis of mild apraxia by the Dabul Apraxia Battery (Dabul, 2000), P2 produced around 10\% phonetic errors. This is close to the range of phonetic errors for patients that Romani \& Galluzzi (2005) classified as apraxic, indicating a phonetic/articulatory disturbance.

Further analysis of P2's repetition errors are indicative of additional phonological or possibly post-lexical impairments. P2's repetition performance on the PRT was 65\% accurate (Table 1). Around a third of his nonword errors were contextual errors, including anticipations, perseverations, or exchanges of phonemes elsewhere in the word. As discussed above, these kinds of errors may be indicative of an impairment in post-lexical sequencing operations or in the timing with which phonemes are retrieved. The rest of P2's nonword errors in repetition were phoneme additions, deletions and substitutions, which can be indicative of problems during phonological retrieval or in phonetic/articulatory processing. Thus, while some of P2's phonological errors may be the result of faulty phonological retrieval, others may have arisen during post-lexical phonological or phonetic/ articulatory encoding.

Materials-The stimuli consisted of forty-eight black-and-white pictures (24 low density/ 24 high density) of common everyday objects named with monosyllabic nouns, largely drawn from Magnuson, Dixon, Tanenhaus, and Aslin, (2007) and Snodgrass and 
Vanderwart (1980; see Appendix A). As a goal of this work was to explore the influence of PND on aphasic speech with more control over the materials than previous work (Best, 1995; Gordon, 2002; Gordon and Dell, 2001; Goldrick et al., 2010; Kittredge et al., 2008) several variables were taken into account in addition to density. The variables assessed in all experiments included number of phonemes, phonotactic probability, familiarity, word frequency, imageability, concreteness, age of acquisition, name agreement and two neighborhood frequency measures: 1 . Average frequency of neighbors; 2 . Presence/absence of higher frequency neighbors. Table 3 reports the average values for these variables and tscores differences between conditions in Experiment 1.

Density, number of phonemes, familiarity, and neighborhood frequency were provided by the Washington University Speech and Hearing Neighborhood Database (directed by Mitch Sommers, Ph.D.; http://neighborhoodsearch.wustl.edu/neighborhood/Home.asp) a webbased interface to the Hoosier Mental Lexicon (Nusbaum, Pisoni, \& Davis, 1984). Density is the number of neighbors similar to the target by the addition, deletion or substitution of one phoneme (Luce \& Pisoni, 1998). The anchors for the familiarity scale include 1=don't know the word; $4=$ recognize the word but don't know its meaning; $7=$ know the word and its meaning. Neighborhood frequency is the average frequency of phonological neighbors. The presence/absence of higher frequency neighbors was calculated using the same database by outputting the phonological neighbors for each item and comparing the frequency of each neighbor against the frequency of the target.

Phonotactic probability is the average sum of positional segment frequency and biphone frequency, retrieved from the Phonotactic Probability Calculator (Vitevitch \& Luce, 2004). Word frequency was taken from the SUBTL frequency norms of American English (Brysbaert \& New, 2009). 1 Imageability values (1=low imagery; 7=high imagery) were taken from Cortese and Fugett (2004), concreteness values (1=highly abstract; $7=$ highly concrete) from Nelson, McEvoy, and Schrieber (2004), and age-of-acquisition ratings from Gilhooly and Logie (1980) and Stadthagen-Gonsalez and Davis (2006). Age-of-acquisition ratings were made on a seven-point scale ranging from 1 ( $0-2$ years) to 7 (13 years and older), with intermediate points on the scale identified with 2-year bands. Imageability values were available for all items in all three experiments, concreteness values were available for at least $92 \%$ of items in each of the three experiments, but age-of-acquisition values were available for no more than $72 \%$ of the items in any of the experiments. Thus, for all missing concreteness or age-of-acquisition values, the mean for the condition (high/low density) per experiment was used. Finally, ten healthy controls provided name agreement responses to all pictures from all three experiments. The pictures were presented in a random order, and participants were asked to name each picture as unambiguously as possible using one word. They were asked to give the label that most accurately described each object.

The only variables besides density that varied between conditions in Experiment 1 by the standard alpha level $p=.05$ were number of phonemes, average neighborhood frequency, and age-of-acquisition (Table 3). Regression analyses (reported in the Results section) were conducted to evaluate potential effects of density on naming performance independent of these confounded variables.

Procedure-In order to increase the number of observations, each participant attempted to name all of the items twice across two sessions, with no less than a 48-hour delay between

\footnotetext{
1In Experiment 1, for the items "can" and "saw" the frequency estimates were dramatically inflated because of homophony and homography with the verbs "can" and "saw". For these two items, their frequency was taken from the Brown Corpus (Francis \& Kucera, 1967) which differentiates word class. The SUBTL frequency norms (Brysbaert \& New, 2009) were used as the frequency estimate for all other items in the three experiments because homophony with high frequency verb forms did not appear to be a problem.
} 
sessions. The pictures were presented randomized in a blocked design, with the order of the high and low density blocks counterbalanced across the two participants and across sessions. Participants were instructed to name the pictures as best they could, and were allowed to continue to try to retrieve the word as long as they felt comfortable, though key measures (e.g., accuracy, error type) were taken upon the first complete (non-fragment) response produced within 30 seconds.

The experiment was presented on a Macintosh computer using Revolution Studio (RunRev Ltd). Participants' verbal responses were digitally recorded and transcribed into IPA by a coder naive to the hypotheses of the experiment. Transcriptions were checked by the first author and discrepancies were resolved by a third coder who was also naïve to the hypotheses of the experiment.

Error Coding-Scoring was adapted from the scheme that is standard for the Philadelphia Naming Test (Roach et al., 1996; see Schwartz et al., 2006 for more details). The same scoring scheme was used for all three experiments. Initial scoring was conducted by a naïve coder, then checked by the first author. A second naïve coder checked all codes and made final decisions regarding any disagreements in coding. A response was coded as accurate if it was produced fully with no phonological errors. African American vernacular variations were accepted as correct. A response was also counted as accurate if a singular was produced in place of a plural or vice versa (e.g., socks for the target sock).

The primary error categories of interest included (1) semantic error, substituted noun that was a synonym of the target, a category coordinate, superordinate/subordinate, or strong associate (e.g., "fire" for the target grill); (2) semantic circumlocution, non-noun or multiword response that conveyed some aspect of the meaning of the word ("little chicken" for the target chick, or "Olympic thing" for torch); (3) formal error, errors that were phonologically related and semantically unrelated to a target but resulted in a word; (4) phonologically-related nonword error, errors that were phonologically related to a target but resulted in a nonword. (Note, a production was judged as phonologically related to a target if it shared at least one phoneme in the same position as the target or two phonemes in any position); (5) mixed error, errors which met the criterion for both semantic and phonologically-related errors. Other error types not included in the main analyses were unrelated errors, nouns that were neither semantically or phonologically-related to the target; picture-part errors, where they named a feature of the picture (these typically reflect a failure to understand what was being shown); no-response errors were when they failed to say anything or say "I don't know."

For the purposes of categorizing naming errors in terms of the two main stages of lexical access, we grouped together semantic errors, semantic circumlocutions, and mixed errors, under the assumption that these errors are indicative of lexical access problems at or above the level of word selection. We also grouped together formals and phonologically-related nonwords, under the assumption that these errors are indicative of problems in phonological processing.

Our classification of formals (i.e., errors that result in phonologically-related words) as arising during phonological processing requires further explanation, due to the noted dualnature of formals (Dell et al., 1997). According to the two-step interactive approach of Dell and colleagues, formal errors can arise during either word selection (e.g., selecting the word "hat" instead of "cat") or phoneme retrieval (e.g., erroneously selecting $/ \mathrm{h} /$, leading to the error "hat" instead of "cat"). To foreshadow the results, in Experiment 1 only a minority of formal errors (35\%) were nouns, a number considerably lower than chance (64\%) estimated as the percentage of nouns in a corpus of monosyllabic words (Gagnon, Schwartz, Martin, 
Dell, \& Saffran, 1997). By comparison, 100\% of the semantic errors produced in this and the following experiments were nouns. Originally noted by Garrett $(1975 ; 1982)$ errors originating during lexical-semantic encoding in production (e.g., semantic errors, whole word substitutions) almost always obey grammatical class constraints whereas phonological level errors are numb to grammatical class.

\section{Results}

Figure 2 reports the proportion of errors in the experimental naming test that were phonologically related or semantically related to the target. The rate of phonologicallyrelated errors was higher for the low density materials for both participant $\mathrm{P} 1, X^{2}(1$, $\mathrm{N}=48)=5.35, p=.02$, and participant $\mathrm{P} 2, X^{2}(1, \mathrm{~N}=48)=3.77, p=.05$. There was a nonsignificant trend for more semantically-related errors for participant $\mathrm{P} 1$ on the low density materials, $X^{2}(1, \mathrm{~N}=48)=2.22, p=.13$. Table 4 gives a full tabulation of all responses in Experiment 1 including raw counts and percentages of correct responses and errors. Accurate responses were significantly higher on the high density materials for participant $\mathrm{P} 1, X^{2}(1, \mathrm{~N}=48)=11.66, p<.001$, and almost significantly higher for participant $\mathrm{P} 2, X^{2}(1$, $\mathrm{N}=48)=3.64, p=.06$.

Backwards stepwise multiple logistic regression was used to model accuracy (error/correct) with density (low/high) as a predictor along with variables that were at least marginally correlated with density in Experiment 1 . These included neighborhood frequency, $r(48)=.29$, $p=.04$, number of phonemes, $r(48)=-.58, p<.001$, and age-of-acquisition, $r(48)=-.40, p<$. 005. Multicollinearity was not of concern in this analysis as indicated by high tolerance values (.58 or greater) for all predictors in the model (Menard, 2002).

In backwards stepwise multiple regression, all predictor variables are entered into the model to evaluate the strength of the predictors simultaneously, after which the predictor that increases the fit of the model the least is removed. If its removal significantly decreases the predictive ability of the model, it is reentered, otherwise it is left out. This process iterates until only useful predictors are included in a final model. For participant P1, density, Wald $X^{2}(1)=3.70, p=.05$, along with number of phonemes, Wald $X^{2}(1)=2.86, p=.09$, were the only predictors retained in the final model (see Appendix B for more information about model fit and predictor statistics). When the model was applied to participant P2's data, only density was retained as a predictor, Wald $X^{2}(1)=3.57, p=.05$.

\section{Discussion}

Experiment 1 revealed that participants P1 and P2 experienced greater difficulty in accurately producing words from low versus high density neighborhoods with more phonologically-related errors produced on targets from low density neighborhoods. Differences in accuracy from the density manipulation obtained even though other lexical factors including familiarity, frequency, phonotactic probability, number of phonemes, neighborhood frequency (two measures), imageability, concreteness, age-of-acquisition and name agreement were controlled either experimentally or statistically. Importantly, as phonotactic probability (position-specific phoneme frequency and bi-phone probability; see Table 3) was controlled between density conditions, the impact of PND has to do with number of phonologically-related neighbors rather than phoneme frequency and transitional probabilities.

These results confirm a facilitative role of PND in the production of words, and is commensurate with other work suggesting that having more phonological neighbors facilitates accurate production in speakers with aphasia (Best, 1995; Goldrick et al., 2010; Gordon \& Dell, 2001; Gordon, 2002; Kittredge et al., 2008), as it does in healthy speakers 
(Vitevitch, 1997; 2002). There also may be subtle semantic effects, with one participant (P1) tending (nonsignificantly) to produce fewer semantically-related errors on the high density (rather than low density) materials. We explore this further in Experiments 2 and 3.

\section{Experiment 2}

Experiment 2 focuses on participant $\mathrm{P} 3$ who is prone to semantic errors during naming. As noted earlier, the interactive two-step framework attributes semantic errors in naming to faulty mapping from semantics to words (the first stage of lexical access). A key prediction of this framework is that density influences this mapping process. Thus, P3 should demonstrate greater accuracy and reduced errors on naming targets from high density neighborhoods. P3 also is impaired on measures of word and picture comprehension, raising the possibility of an additional locus for her semantic errors within the systems that represent or regulate semantic knowledge.

\section{Methods}

\section{Participants (Experiments 2 and 3)}

P3: Participant P3 was a 47-y.o. right-handed female with 18 years of education who had been employed in television before suffering a stroke 52 months prior to time of present testing. She was recruited from the Moss Rehabilitation Research Institute's pool of research volunteers based on prior test results indicating semantic-based disturbances in production and comprehension with unimpaired phonological output. She gave informed consent under a protocol approved the Institutional Review Board of Albert Einstein Healthcare Network of Philadelphia, PA., and was reimbursed $\$ 15$ for each hour of participation. She also consented to undergo a structural MRI or CT imaging to localize her lesion(s). Imaging was conducted at the University of Pennsylvania School of Medicine under their IRB protocol.

Structural imaging (CT) revealed a left-hemisphere lesion localized to the temporoparietal junction (BA 39) and a significant part of the middle temporal gyrus (MTG), extending as far anterior as the temporal pole. A recent study involving voxelwise lesion-symptom mapping identified this region of MTG as important for the production of semantic errors generated during the word selection stage of lexical access (Schwartz et al., 2009).

P3 was classified as having anomic aphasia by the Western Aphasia Battery (WAB; Kertesz, 1982) because she demonstrated high fluency (fluency score $=8$ ), good auditory comprehension (88\%), and relatively preserved repetition (82\%). A clinical screen for speech apraxia (Dabul, 2000) was negative. Other indicators of intact output phonology were above average performance (with respect to patients overall) on tests of word and nonword repetition (Table 1) and low formal and nonword error proportions on the Philadelphia Naming Test (Table 2). The majority of her naming errors were semantic errors, semantic circumlocutions, and mixed errors which may be indicative of a disruption in the mapping from semantics to word representations. Word comprehension was also impaired relative to our larger patient population, as demonstrated by very poor performance on the synonym-matching task and below average performance on a picture-word verification test. P3 also demonstrated very poor performance on the Camels and Cactus test, a test of nonverbal semantic comprehension. Given her poor comprehension performance, a semantic-level contribution to her difficulties in naming performance seems likely.

Materials-As in Experiment 1, the stimuli were black-and-white pictures of common everyday objects named with monosyllabic nouns. Almost all pictures were drawn from Magnuson et al., (2007) or Snodgrass and Vanderwart (1980) with the exception of three 
items (match, bell, grapes) drawn from various internet sources. A subset of items in Experiment 1 was used in Experiment 2 (see Appendix A). The set was reduced to twenty items per density condition with a small number of pictures replaced. Small changes were made in the set of materials from Experiment 1 to Experiment 2 in an effort to further reduce differences between conditions in the many variables analyzed. Numerically, this impacted age-of-acquisition, neighborhood frequency and name agreement the most. Table 5 lists the lexical characteristics of the stimuli, calculated from the same sources described in Experiment 1 . Number of phonemes and age-of-acquisition were reliably different between conditions or approached a significant difference by the standard alpha level $p=.05$ (Table 5). They will be further analyzed in regression analyses reported in the Results.

Procedure and Error Coding-Participant P3 completed the picture naming task twice with a three-week interval between sessions. Distinct from Experiment 1, the pictures were presented in a fully randomized (non-blocked) order each session. Similar to Experiment 1, the participant was instructed to name the pictures as best as possible, and was allowed to continue to try to retrieve the word as long as she felt comfortable. Key measures (e.g., accuracy, error type) were taken upon the first complete (non-fragment) response produced within 30 seconds. All other details of the procedure and error scoring were the same as in Experiment 1.

\section{Results}

Figure 3 reports the proportion of errors that were phonologically related or semantically related to the target. The rate of phonologically-related errors did not differ significantly as a function of density. Of most interest, participant P3 did demonstrate a significantly lower rate of semantically-related errors (semantic errors, mixed, and semantic circumlocutions) on the high density materials, $X^{2}(1, \mathrm{~N}=48)=8.58, p=.003$. The difference in semantic errors alone was reliable, $X^{2}(1, \mathrm{~N}=48)=6.13, p=.013$. Table 6 gives a full tabulation of all responses in Experiment 2 including raw counts and percentages of correct responses and errors.

As in Experiment 1, backwards stepwise multiple logistic regression analysis was conducted with density (high/low) as a predictor along with variables that were at least marginally correlated with it, including number of phonemes, $r(40)=-.50, \mathrm{p}=.001$, and age-ofacquisition, $r(40)=-.29, \mathrm{p}=.06$. Multicollinearity among the predictors was not a problem in this analysis (all tolerance values $>.71$ ). All predictors were retained in the final model: density, Wald $X^{2}(1)=3.81, \mathrm{p}=.05$; number of phonemes, Wald $X^{2}(1)=3.81, \mathrm{p}=.05$; age-ofacquisition, Wald $X^{2}(1)=8.43, \mathrm{p}=.004$ (see Appendix B for model and predictor statistics), demonstrating that density, number of phonemes, and age-of-acquisition each contribute independently to the naming performance of participant P3. We reserve further comment on these results until after Experiment 3.

\section{Experiment 3}

In Experiment 3, we sought to replicate an influence of PND on P3's naming performance with a new set of materials. In the construction of these materials, we achieved tighter experimental control over most of the variables investigated than in the previous two experiments (compare Tables 3, 5, and 7). The most notable changes were in imageability, age-of-acquisition, and neighborhood frequency. We also controlled for homophony, a factor which was not strictly controlled in the first two experiments. Some work suggests that words with a highly frequent homophone counterpart may be facilitated in their production, a phenomenon termed frequency inheritance (Dell, 1990; Jescheniak and Levelt, 1994). Though the questionable reliability of this phenomenon has sparked controversy (Bonin \& Fayol, 2002; Caramazza, Costa, Miozzo \& Bi, 2001; Caramazza, Bi, Costa, \& 
Miozzo, 2004; Jescheniak, Meyer \& Levelt, 2003; Miozzo \& Caramazza, 2005; Miozzo, Jacobs, \& Singer, 2004) the hypothesis of shared phonology between the meanings of a homophone has received support from remediation studies of anomia (Biedermann \& Nickels, 2008). In Experiment 3, we sought to remove the possible confounding influence of frequency inheritance by including only target names that did not have a high frequency homophonic counterpart.

\section{Methods}

Materials, Procedure and Scoring-The stimuli consisted of thirty-two (16 high density/16 low density) colored pictures of common everyday objects named with monosyllabic words (see Appendix A). The pictures came from a colorized version of the Snodgrass and Vanderwart object set (Rossion \& Pourtois, 2004) and various internet sources. Table 7 lists the lexical characteristics of the stimuli used in Experiment 3, calculated from the same sources listed in Experiment 1. Of the variables investigated in addition to density (Table 7) only number of phonemes approached a reliable difference between conditions by the standard alpha level $p=.05$. Its influence on performance will be further investigated in a regression analysis reported in the Results.

Participant P3 performed the task two times in sessions separated by three weeks. All other aspects of the procedure and scoring were the same as described in Experiment 2.

\section{Results}

Table 8 reports the raw counts (and percentages) of all responses as a function of accuracy and error type. Semantically-related errors were elevated for the low density materials versus the high, though this was not statistically reliable, $X^{2}(1, \mathrm{~N}=32)=2.41 p=.12$. P3 also produced 3 phonologically-related errors, specifically formal errors, all of which were in the low density condition. This increase in phonologically-related errors was statistically marginal, $X^{2}(1, \mathrm{~N}=32)=3.14 p=.08$. Overall accuracy was greater for the high density materials versus the low, $X^{2}(1, \mathrm{~N}=32)=3.92 p=.05$. Figure 4 shows the percentage of semantic and phonological errors as a function of density for participant P3.

Among the variables investigated in Experiment 3 (Table 7), only number of phonemes was at least marginally correlated with density condition, $r(32)=-.32, p=.07$. A regression analysis was conducted identical to the first two experiments except that the predictors in the model included only number of phonemes in addition to density (high/low). Among these, only density was retained in the final model, Wald $X^{2}(1)=3.73, p=.05$ (see Appendix B for model and predictor statistics).

\section{Discussion (Experiments 2 \& 3)}

In Experiment 2, participant P3 demonstrated greater naming accuracy on targets from high (versus low) density neighborhoods concomitant with a significant decrease in the incidence of semantically-related errors on these materials. Experiment 3 demonstrated largely similar findings, with greater accuracy and a trend towards fewer semantically-related errors on targets from high versus low density neighborhoods.

The computational account of PND facilitation of lexical access in production (Dell \& Gordon, 2003) explains the decrease in semantic errors to high PND targets in terms of interactive feedback from the phoneme level, which selectively privileges the target word relative to its semantic competitors. While this account was meant to apply to semantic errors generated during word selection, it could also apply to those generated at the semantic level, on the assumption that the semantic-level deficit had the effect of increasing semantic competition for word selection. Concretely, let us suppose that P3 had a tendency to produce 
DOG for CAT because her concepts for these animals lacked distinguishing features (a semantic level deficit). If this resulted in greater competition between DOG and CAT at the word level, then the phonological feedback to neighbors CAT and MAT would benefit CAT over DOG and thus decrease the likelihood of the semantic error.

Could interactive feedback also percolate upwards from the word level to promote better target conceptualization directly? We find this possibility unlikely. First, it is not obvious how a semantic impairment involving missing or unavailable semantic features could be corrected by feedback from phonologically-related (and semantically-unrelated) words. In a situation where multiple semantically related concepts are activated (e.g., cat, dog), but distinguishing features are lacking, feedback from phonologically related neighbors could bolster activation of a target concept. However, this requires the assumption of sufficient feedback from word-level to semantic representations. Work by Rapp and Goldrick (2000) demonstrated through simulations that there is little if any feedback from words to semantics during naming. Thus, we find it more likely that the effect of PND on P3's naming performance is due to the impact of phonologically related neighbors on word selection rather than on conceptualization itself.

\section{General Discussion}

The current work established the influence of phonological neighborhood density on aphasic naming performance while controlling for a broader range of extraneous variables than in previous work on PND effects in aphasia (Best, 1995; Goldrick et al., 2010; Gordon, 2002; Gordon and Dell, 2001; Kittredge et al., 2008). In the present studies, an influence of PND on aphasic naming performance was established independent of familiarity, phonotactic probability, word frequency, homophony, number of phonemes, syllable length, age-ofacquisition, concreteness, imageability, name agreement and two measures of neighborhood frequency.

In Experiment 1, we focused on two participants with aphasia secondary to a lefthemisphere cerebrovascular accident whose naming impairment manifested in a tendency for phonologically-related errors. Closer analysis of their repetition errors suggested that participant P1 primarily had a deficit in the retrieval of constituent phonemes, whereas P2 had additional phonetic/articulatory problems possibly concomitant with impaired postlexical buffering/sequencing operations. On the experimental task, both participants were more accurate in naming targets from high (versus low) density neighborhoods, due largely to a reduction in phonological errors. Thus, the PND manipulation at a minimum facilitated phonological retrieval from the lexicon (P1) and it may have facilitated post-lexical phonological and phonetic operations as well (P2). The possibility that the PND effect in P2 was actually due to sublexical properties confounded with PND is made much less likely by the fact that high and low density targets were equated for phonotactic probability, (i.e., position-specific phoneme frequency and the frequency of particular phoneme sequences). While it remains possible that some other sublexical confound was responsible for the PND effect in P2, the more likely explanation is that the responsible factor is indeed phonological neighbors: when there are more neighbors, there are more lexical-phonological feedback loops created, resulting in greater convergence onto the target phonemes. In patients like P2, this could also benefit damaged processes at subsequent levels of phonological and phonetic encoding. For example, with more feedback loops engaged, evidence might accumulate faster for the target's constituent phonemes, allowing post-lexical and phonetic/articulatory processes to initiate earlier than with fewer feedback loops engaged.

Experiments 2 and 3 addressed whether phonologically related neighbors also impact processing during the mapping from semantics to word representations. The participant in 
these experiments, $\mathrm{P} 3$, was prone to semantic errors in naming and comprehension. In two experiments involving different sets of materials, her naming performance was more accurate on targets from high density neighborhoods compared to low, and the increased accuracy with high density targets was generally associated with a decrease in semantically related errors.

An influence of the number of phonologically related neighbors on the naming performance of P3 - whose neuropsychological profile implicates semantic and not phonological-level processes --constitutes very strong evidence for interactive approaches to lexical access (Dell, 1986; Dell et al., 1997; Dell \& Gordon, 2003; Foygel \& Dell, 2000; Harley, 1993b; Rapp \& Goldrick, 2000; Schwartz et al., 2006; Stemberger, 1985)). The interpretation of this finding is that a target that hails from a high (versus low) density neighborhood receives more activation from phonological neighbors by fiat of interactive activation through shared phonemes. Activation from phonologically related neighbors serves to boost accurate selection of a target word while providing little to no benefit to semantically related (but largely phonologically unrelated) competitors. Whatever the locus of the deficit, lexical or semantic, as long as it predisposes to semantic errors by reducing the advantage of the target word (relative to its semantic competitors) one would expect a benefit from this targetboosting consequence of phonological feedback. Hence, there is no need to postulate that phonological feedback percolates all the way up to semantics in order to accommodate the possibility that $\mathrm{P} 3$ 's naming problem was semantically based.

Our results pose difficulty for feedforward approaches to lexical access (Butterworth, 1989; Levelt et al., 1991, 1999; Roelefs, 1992, 1997, 2004). At most, such models allow for activation to cascade from semantically-activated word units (target and semantic neighbors) to the phonemes that constitute these words. Without interaction, there is no direct way for the target's phonological neighbors to become involved, and thus no explanation for why the number of phonological neighbors should impact naming accuracy. One option such models have is to postulate that the PND effect reduces to a confounding influence of phonotactic probability or other sublexical factors. The present results render this implausible, for these reasons: First, we controlled for phonotactic probability in all three experiments; and second, we demonstrated that PND-based facilitation was not limited to the patient with possible phonetic/articulatory problems (P2) but was present in robust fashion in a patient with a specific deficit in phonological retrieval (P2) and, more compelling still, in P3. It is difficult to imagine how the effects obtained with P3 could reduce to sublexical factors, as she has no discernible phonological disruptions of any kind.

A second recourse for feedforward models is to postulate that phonological neighbors are activated indirectly, through pre-articulatory monitoring through the comprehension system (e.g., Levelt et al., 1999). We will consider this further below, in the context of other arguments favoring interactivity.

\section{Interactivity in Word Production}

Interactivity is an important mechanism for explaining a number of phenomena in the word production literature in addition to PND effects. One such phenomenon is the mixed error effect, an observation that semantically-related errors tend to be phonologically related more often than would be expected by chance (Dell and Reich, 1981; Martin, Gagnon, Schwartz, Dell, \& Saffran, 1996). This phenomenon suggests that lexical access is not strictly feedfoward. Rather, phonologically-related semantic competitors receive a boost in activation from feedback through shared phonological representations with a target, heightening the likelihood of their selection resulting in an error. 
Another phenomenon often explained as demonstrative of interactivity is the lexical bias effect, a finding that phonological speech errors are more likely if they result in words than nonwords, and that this tendency is greater than what would be predicted by chance (Baars et al., 1975; Dell \& Reich, 1981; Hartsuiker, Anton-Mendez, Roelstraete, \& Costa, 2006; Oppenheim \& Dell, 2008; see Rapp \& Goldrick, 2000, for discussion). The lexical bias effect has been established in controlled experimental settings (Baars et al., 1975; Costa, Roelstraete, \& Hartsuiker, 2006; Hartsuiker et al., 2006; Oppenheim \& Dell, 2008) as well as in natural speech corpora (Dell \& Reich, 1981; Hartsuiker et al., 2006). The traditional procedure for investigating the lexical bias effect experimentally is the SLIP task (Baars et al., 1975). In this task, participants read word pairs (e.g., lead-real, love-rock, lard-read) silently and are signaled to overtly produce some pairs such as reef-leech, a procedure which primes an onset exchange error (e.g., reef-leech $\rightarrow$ leaf reach). A main finding in these kinds of studies is that onset exchange errors that result in words (e.g., reef leech $\rightarrow$ leaf reach) are more likely than exchange errors that result in nonwords (e.g., sheaf teach $\rightarrow$ teef sheach) when the opportunity for both kinds of errors is equated. This has been taken as evidence for interactivity, where an unintended phoneme in a particular syllable position will be more likely to be selected in error if it is reciprocating activation to and from a word node (versus when a word node is absent).

An interesting question is how the mixed error effect, lexical bias and density effects may be incorporated into a unified account of lexical access. In the mixed error effect, phonologically-related semantic competitors pose difficulty in accurate encoding at lexicosemantic level processes. In lexical bias, an error is more likely if it results in a word than a nonword, suggesting that lexical level representations can induce errors. Why then do phonologically-related neighbors not induce their own degree of competition, where accuracy decreases with increasing density? The explanation proposed here, which is also consistent with views of Dell and Gordon (2003), is that phonologically-related neighbors do introduce some degree of competition, but that their facilitative effects are stronger than their competitive effects. One reason to expect this is that in the very same SLIP procedure in which the lexical bias effect has been established, Vitevitch (2002, Experiment 1) found that more speech errors were elicited for word pairs from sparse rather than dense phonological neighborhoods, suggesting that having many versus few form related neighbors facilitates accurate production in the SLIP task. Likewise, Vitevitch (1997) found that malapropisms (form related word substitutions such as insulation $\rightarrow$ installation) are more likely to involve words from low rather than high density neighborhoods.

On the other hand, evidence suggests that greater density is not always associated with better performance. Vitevitch, Armbruster \& Chu (2004) found that words with high rather than low onset density (controlling for overall neighborhood density) were associated with slower naming time in healthy adults. Newman and German $(2002,2005)$ reported poorer accuracy in naming with high versus low density materials in children and adults. Thus more research is necessary to delineate the situations where phonological neighbors hurt, rather than help, and to specify the dynamics of phonological neighborhoods. For example, there may be a lower bound to facilitation from neighbors so that having one closely related phonological neighbor is worse than having none. Furthermore, at what point does the cumulative facilitation of multiple phonologically-related neighbors offset and overwhelm the competitive factors, and what is the role of distantly related phonological neighbors? (For suggestions, see Mirman, Kittredge \& Dell, 2010).

In the present work, we interpret our results as support for an interactive account of lexical access, which is at odds with feedforward approaches. Phenomena such as the lexical bias effect, which have been taken as support for interactivity, instead are explained in terms of the workings of a monitoring system. For example, in the WEAVER++ model by Levelt et 
al., (1999) the lexical bias effect results not from interactivity but from a monitoring system which edits a pre-articulatory representation for lexicality, covertly filtering out nonword errors more so than word errors. At present the debate continues whether interactivity or a monitoring approach (or a combination of both, Hartsuiker, Corley, \& Martensen, 2005) offer the best account of the lexical bias effect (Baars et al., 1975; Nooteboom, 2005; Nozari \& Dell, 2009; Roelefs, 2004; Rapp \& Goldrick, 2000; Severens, Ratinckx, Ferreira, \& Hartsuiker, 2008). However, PND effects may be incompatible with predictions of a selfmonitoring mechanism. For example, according to WEAVER++, the mixed error effect arises because the internal monitor has a more difficult time discriminating RAT from CAT than DOG from CAT, due to heightened perceptual similarity. If so, by this account phonologically-related errors (formals in particular) should be more likely when producing targets from high (rather than low) density neighborhoods because an erroneously selected lemma is more likely to be phonologically similar to (and thus more difficult to discriminate from) the target. This expectation is clearly not supported by the extant data, including the current results. Settling these issues is beyond the scope of this paper, but these considerations do highlight the potentially considerable theoretical relevance of phonological neighborhood density effects in informing larger debates about the essential nature of lexical access.

\section{Acknowledgments}

This work was supported by the National Institutes of Health (RO1 DC000191 to MFS and 5-T32-HD-007425 to the University of Pennsylvania). Many thanks to Dr. Mitch Sommers for assistance using the Washington University in St. Louis Speech and Hearing Lab Neighborhood Database. Thanks go also to Rachel Jacobson and Adelyn Brecher for assistance in data collection, transcription and coding, Grant Walker for assistant in characterizing participants' lesions, and all members of the Language and Aphasia Lab for their feedback throughout the development of this project.

\section{References}

Baars BJ, Motley JT, MacKay D. Output editing for lexical status from artificially elicited slips of the tongue. Journal of Verbal Learning and Verbal Behavior. 1975; 14:382-391.

Badecker W, Miozzo M, Zanuttini R. The two-stage model of lexical retrieval: Evidence from a case of anomia with selective preservation of grammatical gender. Cognition. 1995; 57:193-216. [PubMed: 8556841]

Baus C, Costa A, Carreiras M. Neighbourhood density and frequency effects in speech production: a case for interactivity. Language and Cognitive Processes. 2008; 23:866-888.

Biedermann B, Nickels L. The representation of homophones: More evidence from the remediation of anomia. Cortex. 2008; 44:276-293. [PubMed: 18387557]

Best WM. A reverse length effect in dysphasic naming: When elephant is easier than ant. Cortex. 1995; 31:637-652. [PubMed: 8750023]

Bonin P, Fayol M. Frequency effects in the written and spoken production of homophonic picture names. European Journal of Cognitive Psychology. 2002; 14:289-313.

Bozeat S, Lambon-Ralph MA, Patterson K, Garrard P, Hodges JR. Nonverbal semantic impairment in semantic dementia. Neuropsychologia. 2000; 38:1207-1215. [PubMed: 10865096]

Brysbaert M, New B. Moving beyond Kucera and Francis: A critical evaluation of current word frequency norms and the introduction of a new and improved word frequency measure for American English. Behavior Research Methods. 2009; 41:977-990. [PubMed: 19897807]

Buckingham HW. The scan-copier mechanism and the positional level of language production: Evidence from phonemic paraphasia. Cognitive Science. 1986; 10:195-217.

Burke DM, MacKay DG, Worthley JS, Wade E. On the tip of the tongue: What causes word finding failures in young and older adults? Journal of Memory and Language. 1991; 30:542-579.

Butterworth, B. Lexical access in speech production. In: Marslen-Wilson, W., editor. Lexical representation and process. Cambridge, MA: MIT Press; 1989. 
Caramazza A. How many levels of processing are there in lexical access? Cognitive Neuropsychology. 1997; 14:177-208.

Caramazza A, Bi Y, Costa A, Miozzo M. What determines the speed of lexical access: Homophone or specific-word frequency? A reply to Jescheniak et al. (2003). Journal of Experimental Psychology: Learning, Memory, \& Cognition. 2004; 30:278-282.

Caramazza A, Costa A, Miozzo M, Bi Y. The specific-word frequency effect: implications for the representations of homophones in speech production. Journal of Experimental Psychology: Learning, Memory, and Cognition. 2001; 27:1430-1450.

Cortese MJ, Fugett A. Imageability rating for 3,000 monosyllabic words. Behavior Research Methods, Instruments, \& Computers. 2004; 36:384-387.

Costa A, Roelstraete B, Hartsuiker RJ. The lexical bias effect in bilingual speech production: Evidence for feedback between lexical and sublexical levels across languages. Psychonomic Bulletin and Review. 2006; 13:972-977. [PubMed: 17484421]

Dabul, B. Apraxia battery for adults. Austin, Tx: Pro-Ed; 2000.

Dell GS. A spreading activation theory of retrieval in sentence production. Psychological Review. 1986; 93:283-321. [PubMed: 3749399]

Dell GS. Effects of frequency and vocabulary type on phonological speech errors. Language and Cognitive Processes. 1990; 5:315-349.

Dell, GS.; Gordon, JK. Neighbors in the lexicon: Friends or foes. In: Schiller, NO.; Meyer, AS., editors. Phonetics and phonology in language comprehension and production: Differences and similarities. Berlin: Mouton de Gruyter; 2003.

Dell GS, Martin N, Schwartz MF. A case-series test of the interactive two-step model of lexical access: Predicting word repetition from picture naming. Journal of Memory and Language. 2007; 56:490-520. [PubMed: 21085621]

Dell GS, O'Seaghdha PG. Stages of lexical access in speech production. Cognition. 1992; 42:287-314. [PubMed: 1582160]

Dell GS, Reich PA. Stages in sentence production: An analysis of speech error data. Journal of Verbal Learning and Verbal Behavior. 1981; 20:611-629.

Dell GS, Schwartz M, Martin M, Saffran EM, Gagnon DA. Lexical access in aphasic and nonaphasic speakers. Psychological Review. 1997; 104:801-838. [PubMed: 9337631]

Fay D, Cutler A. Malapropisms and the structure of the mental lexicon. Linguistic Inquiry. 1977; 8:505-520.

Foygel D, Dell GS. Models of impaired lexical access in speech production. Journal of Memory and Language. 2000; 43:182-216.

Francis, WN.; Kucera, H. Computational analysis of present-day American English. Brown University Press; 1967. Providence

Fromkin VA. The non-anomalous nature of anomalous utterances. Language. 1971; 47:27-52.

Gagnon DA, Schwartz MF, Martin N, Dell GS, Saffran EM. The origins of formal paraphasias in aphasics' picture naming. Brain and Language. 1997; 59:450-472. [PubMed: 9299072]

Gainotti G, Miceli G, Caltagirone C, Silveri MC, Masullo C. The relationship between type of naming error and semantic-lexical discrimination in aphasic patients. Cortex. 1981; 17:401-410. [PubMed: 7333113]

Garrett, MF. The analysis of sentence production. In: Bower, G., editor. Psychology of learning and motivation. Vol. Vol. 9. New York: Academic Press; 1975.

Garrett, MF. Production of speech: Observations from normal and pathological language use. In: Ellis, AW., editor. Normality and pathology in cognitive functions. London: Academic Press; 1982. p. 19-76.

German DJ, Newman RS. The impact of lexical factors on children's word-finding errors. Journal of Speech, Language, and Hearing Research. 2004; 47:624-636.

Gilhooly KJ, Logie RH. Age-of-acquisition, imagery, concreteness, familiarity, and ambiguity measures for 1,944 words. Behavior Research Methods \& Instrumentation. 1980; 12:395-427. 
Goldrick M, Folk JR, Rapp B. Mrs. Malaprop's neighborhood: Using word errors to reveal neighborhood structure. Journal of Memory and Language. 2010; 62:113-134. [PubMed: 20161591]

Goldrick M, Rapp B. Lexical and post-lexical phonological representations in spoken production. Cognition. 2007; 102:219-260. [PubMed: 16483561]

Gordon JK. Phonological neighborhood effects in aphasic speech errors: spontaneous and structured contexts. Brain and Language. 2002; 82:113-145. [PubMed: 12096871]

Gordon JK, Dell GS. Phonological neighbourhood effects: Evidence from aphasia and connectionist modeling. Brain and Language. 2001; 79:21-23.

Harley TA. Connectionist approaches to language disorders. Aphasiology. 1993a; 7:221-249.

Harley TA. Phonological activation of semantic competitors during lexical access in speech production. Language and Cognitive Processes. 1993b; 8:291-309.

Harley TA, Bown HE. What causes a tip-of-the-tongue state? Evidence for lexical neighbourhood effects in speech production. British Journal of Psychology. 1998; 89:151-174.

Hart J, Gordon B. Delineation of single-word semantic comprehension deficits in aphasia, with anatomical correlation. Annals of Neurology. 1990; 27:226-231. [PubMed: 2327733]

Hartsuiker RJ, Anton-Mendez I, Roelstraete B, Costa A. Spoonish spanerisms: A lexical bias effects in Spanish. Journal of Experimental Psychology: Learning, Memory and Cognition. 2006; 32:949953.

Hartsuiker RJ, Corley M, Martensen H. The lexical bias effect is modulated by context, but the standard monitoring account doesn't fly: Related reply to Baars, Motley, and MacKay (1975). Journal of Memory and Language. 2005; 52:58-70.

Hillis AE, Rapp BC, Romani D, Caramazza A. Selective impairment of semantics in lexical processing. Cognitive Neuropsychology. 1990; 7:191-243.

James LE, Burke DM. Phonological priming effects on word retrieval and tip-of-the-tongue experiences in young and older adults. Journal of Experimental Psychology: Learning, Memory, and Cognition. 2000; 26:1378-1392.

Jefferies E, Lambon Ralph MA. Semantic impairment in stroke aphasia versus semantic dementia: a case-series comparison. Brain. 2006; 129:2132-2147. [PubMed: 16815878]

Jescheniak JD, Levelt WJM. Word frequency effects in speech production: Retrieval of syntactic information and of phonological form. Journal of Experimental Psychology: Learning, Memory, and Cognition. 1994; 20:824-843.

Jescheniak JD, Meyer AS, Levelt WJM. Specific-word frequency is not all that counts in speech production: Comments on Caramazza, Costa, et al. (2001) and new experimental data. Journal of Experimental Psychology: Learning, Memory, and Cognition. 2003; 29:432-438.

Kempen G, Huijbers P. The lexicalization process in sentence production and naming: Indirect election of words. Cognition. 1983; 14:185-209.

Kertesz, A. Western aphasia battery. New York: Grune \& Stratton; 1982.

Kittredge AK, Dell GS, Verkuilen J, Schwartz M. Where is the effect of frequency in word production? Insights from aphasic picture-naming errors. Cognitive Neuropsychology. 2008; 25:463-492. [PubMed: 18704797]

Kohn SE, Smith KL. Between-word speech errors in conduction aphasia. Cognitive Neuropsychology. 1990; 7:133-156.

Levelt, WJM. Speaking: From intention to articulation. Cambridge, MA: MIT Press; 1989.

Levelt WJM, Roelofs A, Meyer AS. A theory of lexical access in speech production. Behavioral and Brain Sciences. 1999; 22:1-75. [PubMed: 11301520]

Levelt WJM, Schriefers H, Vorberg D, Meyer AS, Pechmann T, Havinga J. The time course of lexical access in speech production: A study of picture naming. Psychological Review. 1991; 98:122-142.

Luce PA, Pisoni DB. Recognizing spoken words: The neighborhood activation model. Ear and Hearing. 1998; 19:1-36. [PubMed: 9504270]

Magnuson JS, Dixon JA, Tanenhaus MK, Aslin RN. The dynamics of lexical competition during spoken word recognition. Cognitive Science. 2007; 31:1-24. [PubMed: 21635286] 
Martin N, Gagnon DA, Schwartz MF, Dell GS, Saffran EM. Phonological facilitation of semantic errors in normal and aphasic speakers. Language and Cognitive Processes. 1996; 11:257-282.

Menard, S. Quantitative Applications in the Social Sciences. Vol. Vol. 106. Thousand Oaks, CA: Sage University; 2002. Applied logistic regression analysis--2nd ed..

Meyer AS, Bock JK. The tip-of-the-tongue phenomenon: Blocking or partial activation? Memory \& Cognition. 1992; 20:715-726.

Miozzo M, Caramazza A. The representation of homophones: Evidence from the distractor-frequency effect. Journal of Experimental Psychology: Learning, Memory, and Cognition. 2005; 31:13601371.

Miozzo M, Jacobs ML, Singer NJW. The representation of homophones: Evidence from anomia. Cognitive Neuropsychology. 2004; 21:840-866. [PubMed: 21038236]

Mirman, D.; Kittredge, AK.; Dell, GS. Effects of near and distant phonological neighbors on picture naming. In: Ohlsson, S.; Catrambone, R., editors. Proceedings of the 32nd Annual Conference of the Cognitive Science Society; Austin, TX: Cognitive Science Society; 2010. p. 1447-1452.

Nozari N, Dell GS. More on lexical bias: How efficient can a "lexical editor" be? Journal of Memory and Language. 2009; 60:291-307. [PubMed: 20126302]

Nelson DL, McEvoy CL, Schrieber TA. The University of South Florida free association, rhyme, and word fragment norms. Behavior Research Methods, Instruments, \& Computers. 2004; 36:402407.

Newman RS, German DJ. Effects of lexical factors on lexical access among typical language-learning children and children with word-finding difficulties. Language \& Speech. 2002; 43:285-317.

Newman RS, German DJ. Life span effects of lexical factors on oral naming. Language \& Speech. 2005; 48:123-156. [PubMed: 16411502]

Nooteboom, SG. Listening to oneself: Monitoring speech production. In: Hartsuiker, RJ.; Bastiaanse, R.; Postma, A.; Wijnen, F., editors. Phonological encoding and monitoring in normal and pathological speech. Hove, England: Psychology Press; 2005. p. 167-186.

Nusbaum HC, Pisoni DB, Davis CK. Sizing up the Hoosier mental lexicon: Measuring the familiarity of 20,000 words. Indiana University, Psychology Department, Speech Research Laboratory. Research on Speech Perception, Progress Rep. 1984; (No. 10)

Oppenheim GM, Dell GS. Inner speech slips exhibit lexical bias but not the phonemic similarity effect. Cognition. 2008; 106:528-537. [PubMed: 17407776]

Peterson RR, Savoy P. Lexical selection and phonological encoding during language production: Evidence for cascaded processing. Journal of Experimental Psychology: Learning, Memory, and Cognition. 1998; 24:539-557.

Rapp B, Goldrick M. Discreteness and interactivity in spoken word production. Psychological Review. 2000; 107:460-499. [PubMed: 10941277]

Roach A, Schwartz MF, Martin N, Grewal RS, Brecher A. The Philadelphia naming test: scoring and rationale. Clinical Aphasiology. 1996; 24:121-133.

Roelofs A. A spreading-activation theory of lemma retrieval in speaking. Cognition. 1992; 42:107142. [PubMed: 1582154]

Roelofs A. The WEAVER model of word-form encoding in speech production. Cognition. 1997; 64:249-284. [PubMed: 9426503]

Roelofs A. Error biases in spoken word planning and monitoring by aphasic and nonaphasic speakers: comment on Rapp and Goldrick (2000). Psychological Review. 2004; 111:561-572. [PubMed: 15065924]

Romani C, Galluzzi C. Effects of syllabic complexity in predicting accuracy of repetition and direction of errors in patients with articulatory and phonological difficulties. Cognitive Neuropsychology. 2005; 22:817-850. [PubMed: 21038278]

Rossion B, Pourtois G. Revisiting Snodgrass and Vanderwart's object pictorial set: The role of surface detail in basic-level object recognition. Perception. 2004; 33:217-236. [PubMed: 15109163]

Ruml W, Caramazza A, Capasso R, Miceli G. Interactivity and continuity in normal and aphasic language production. Cognitive Neuropsychology. 2005; 22:131-168. [PubMed: 21038244] 
Schriefers H, Meyer AS, Levelt WJM. Exploring the time course of lexical access in production: Picture-word interference studies. Journal of Memory and Language. 1990; 29:86-102.

Schwartz MF, Dell GS, Martin N, Gahl S, Sobel P. A case-series test of the interactive two-step model of lexical access: Evidence from picture naming. Journal of Memory and Language. 2006; 54:228-264.

Schwartz MF, Kimberg DY, Walker GM, Faseyitan O, Brecher A, Dell GS, Coslett HB. Anterior temporal involvement in semantic word retrieval: voxel-based lesion-symptom mapping evidence from aphasia. Brain. 2009; 132:3411-3427. [PubMed: 19942676]

Schwartz MF, Wilshire CE, Gagnon DA, Polansky M. Origins of nonword phonological errors in aphasic picture naming. Cognitive Neuropsychology. 2004; 21:159-186. [PubMed: 21038198]

Severens E, Ratinckx E, Ferreira V, Hartsuiker RJ. Are phonological influences on lexical (mis)selection the result of a monitoring bias? Quarterly Journal of Experimental Psychology. 2008; 61:1687-1709.

Shallice T, Rumiati RI, Zadini A. The selective impairment of the phonological output buffer. Cognitive Neuropsychology. 2000; 17:517-546. [PubMed: 20945193]

Snodgrass JG, Vanderwart M. A standardized set of 260 pictures: Norms for name agreement, image agreement, familiarity, and visual complexity. Journal of Experimental Psychology: Human Learning and Memory. 1980; 6:174-215. [PubMed: 7373248]

Sommers, MS. Washington University in St. Louis Speech and Hearing Lab Neighborhood Database: A web-based implementation of the 20,000-word Hoosier Mental Lexicon. URL:http://neighborhoodsearch.wustl.edu/neighborhood/Home.asp.

Stadthagen-Gonzalez H, Davis CJ. The Bristol norms for age of acquisition, imageability, and familiarity. 2006; 38:598-605.

Stemberger, JP. An interactive activation model of language production. In: Ellis, AW., editor. Progress in the psychology of language. Vol. Vol. 1. Hillsdale, NJ: Erlbaum; 1985. p. 143-186.

Vigliocco G, Antonini T, Garrett MF. Grammatical gender is on the tip of Italian tongues. Psychological Science. 1997; 8:314-317.

Vigliocco G, Hartsuiker RJ. The interplay of meaning, sound, and syntax in sentence production. Psychological Bulletin. 2002; 128:442-472. [PubMed: 12002697]

Vitevitch MS. The neighborhood characteristics of malapropisms. Language and Speech. 1997; 40:211-228. [PubMed: 9509578]

Vitevitch MS. The influence of phonological similarity neighborhoods on speech production. Journal of Experimental Psychology: Learning, Memory, and Cognition. 2002; 28:735-747.

Vitevitch MS, Armbruster J, Chu S. Sublexical and lexical representations in speech production: Effects of phonotactic probability and onset density. Journal of Experimental Psychology: Learning, Memory, and Cognition. 2004; 30:514-529.

Vitevitch MS, Luce PA. When words compete: Levels of processing in spoken word perception. Psychological Science. 1998; 9:325-329.

Vitevitch MS, Luce PA. Probabilistic phonotactics and spoken word recognition. Journal of Memory and Language. 1999; 40:374-408.

Vitevitch MS, Luce PA. A web-based interface to calculate phonotactic probability for words and nonwords in English. Behavior Research Methods, Instruments, and Computers. 2004; 36:481487.

Vitevitch MS, Sommers MS. The facilitative influence of phonological similarity and neighborhood frequency in speech production in younger and older adults. Memory and Cognition. 2003; 31:491-504.

\title{
Appendix A: Materials (Experiments 1-3)
}

\author{
Experiments 1 and 2 \\ Low Density Materials *Saw
}

Cogn Neuropsychol. Author manuscript; available in PMC 2011 July 8. 


\begin{tabular}{|c|c|}
\hline *Bolt & Sheep \\
\hline Clown & Sock \\
\hline$* *$ Couch & Vase \\
\hline Crown & Vest \\
\hline Crutch & Witch \\
\hline \multicolumn{2}{|l|}{ Drill } \\
\hline Flag & *Experiment 1 only \\
\hline Fork & $* *$ Experiment 2 only \\
\hline \multicolumn{2}{|l|}{ Fox } \\
\hline Goose & Experiment 3 \\
\hline Grill & Low Density Materials \\
\hline *Groom & $\mathrm{Bib}$ \\
\hline Hook & Cage \\
\hline Plug & Chess \\
\hline Pump & Dog \\
\hline *Shield & Hand \\
\hline Skate & Harp \\
\hline Skull & Horse \\
\hline Stump & Jar \\
\hline Throne & Peach \\
\hline Thumb & Pig \\
\hline Torch & Robe \\
\hline$*$ Trunk & Shark \\
\hline$*$ Vice & Soap \\
\hline \multirow[t]{3}{*}{ Wreath } & Tray \\
\hline & Tree \\
\hline & Yarn \\
\hline \multicolumn{2}{|c|}{ High Density Materials } \\
\hline \multicolumn{2}{|l|}{$* *$ Bell } \\
\hline *Bear & High Density Materials \\
\hline Bull & Bed \\
\hline Cake & Bone \\
\hline Calf & Car \\
\hline$*^{*}$ Can & Chair \\
\hline Cane & Cheese \\
\hline Cart & Cone \\
\hline Chick & Corn \\
\hline$*$ Deer & Door \\
\hline Goat & Hat \\
\hline Grapes & Map \\
\hline Knight & Rake \\
\hline **Match & Rat \\
\hline Mop & Rope \\
\hline
\end{tabular}

Cogn Neuropsychol. Author manuscript; available in PMC 2011 July 8. 


\begin{tabular}{ll} 
*Nail & Rug \\
Net & Shell \\
Nun & Wheel \\
Pan & \\
*Pear & \\
\hline
\end{tabular}

\section{Appendix B: Regression model results (Experiments 1-3)}

\begin{tabular}{|c|c|c|c|c|c|c|}
\hline \multicolumn{7}{|c|}{ Regression results for Participant P1 (Experiment 1) } \\
\hline Predictors retained & $\boldsymbol{\beta}$ & $S E \beta$ & Wald's $X^{2}$ & $d f$ & $p$ & $\underset{\text { (odds ratio }}{e \beta}$ \\
\hline Constant & 2.70 & 1.67 & 2.61 & 1 & .10 & 14.89 \\
\hline Number of phonemes & -.71 & .42 & 2.86 & 1 & .09 & .48 \\
\hline Phonological density & 1.05 & .54 & 3.70 & 1 & .05 & 2.87 \\
\hline Overall model evaluation & & & $X^{2}$ & $d f$ & $p$ & \\
\hline Likelihood ratio test & & & 14.90 & 2 & .001 & \\
\hline \multicolumn{7}{|c|}{ Regression results for Participant $P 2$ (Experiment 1$)$} \\
\hline Predictors retained & $\beta$ & $S E \beta$ & Wald's $X^{2}$ & $d f$ & $p$ & $\begin{array}{c}e^{\beta} \\
\text { (odds ratio) }\end{array}$ \\
\hline Constant & .16 & .29 & .33 & 1 & .56 & 1.18 \\
\hline Phonological density & .82 & .43 & 3.57 & 1 & .05 & 2.27 \\
\hline Overall model evaluation & & & $X^{2}$ & $d f$ & $p$ & \\
\hline Likelihood ratio test & & & 3.67 & 1 & .05 & \\
\hline \multicolumn{7}{|c|}{ Regression results for Participant P3 (Experiment 2) } \\
\hline Predictors retained & $\beta$ & $S E \beta$ & Wald's $X^{2}$ & $d f$ & $p$ & $\begin{array}{c}e^{\beta} \\
\text { (odds ratio) }\end{array}$ \\
\hline Constant & .20 & 2.48 & .007 & 1 & .93 & 1.22 \\
\hline Age-of-acquisition & -1.81 & .62 & 8.43 & 1 & .004 & .16 \\
\hline Number of phonemes & 1.13 & .58 & 3.81 & 1 & .05 & 3.12 \\
\hline Phonological density & 1.26 & .64 & 3.81 & 1 & .05 & 3.54 \\
\hline Overall model evaluation & & & $X^{2}$ & $d f$ & $p$ & \\
\hline Likelihood ratio test & & & 16.54 & 3 & .001 & \\
\hline \multicolumn{7}{|c|}{ Regression results for Participant P3 (Experiment 3 ) } \\
\hline Predictors retained & $\beta$ & $S E \beta$ & Wald's $X^{2}$ & $d f$ & $p$ & $\begin{array}{c}e^{\beta} \\
\text { (odds ratio) }\end{array}$ \\
\hline Constant & .51 & .36 & 1.95 & 1 & .16 & 1.66 \\
\hline Phonological density & 1.17 & .60 & 3.73 & 1 & .05 & 3.24 \\
\hline Overall model evaluation & & & $X^{2}$ & $d f$ & $p$ & \\
\hline Likelihood ratio test & & & 4.01 & 1 & .04 & \\
\hline
\end{tabular}

Cogn Neuropsychol. Author manuscript; available in PMC 2011 July 8. 


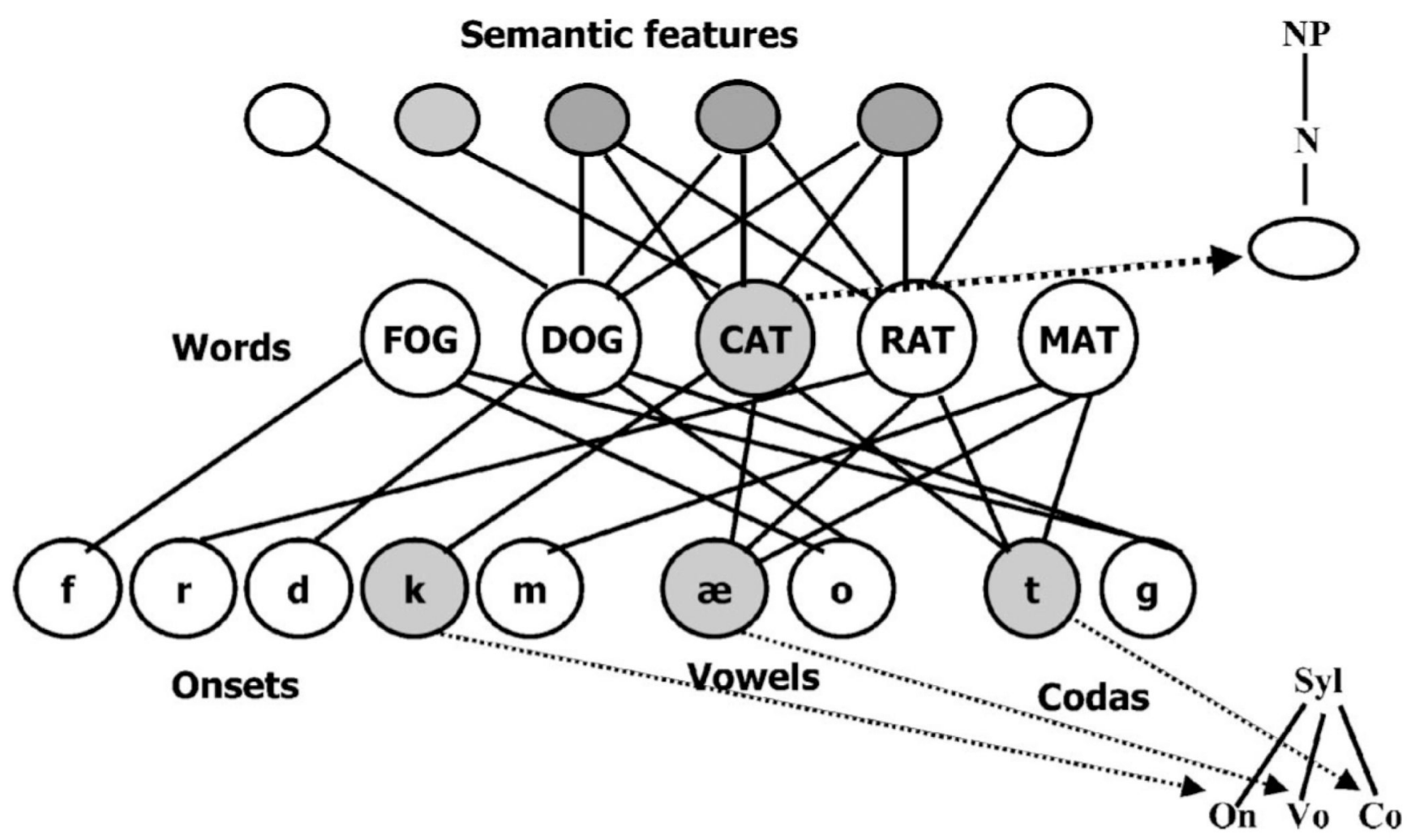

Figure 1.

The two-step interactive theory of word retrieval. See text for description. From "A caseseries test of the interactive two-step model of lexical access: Evidence from picture naming," by M. F. Schwartz, G. S. Dell, N. Martin, S. Gahl, and P. Sobel, 2006, Journal of Memory and Language, 54, p. 230. Copyright 2006 by Elsevier. Reprinted with permission. 

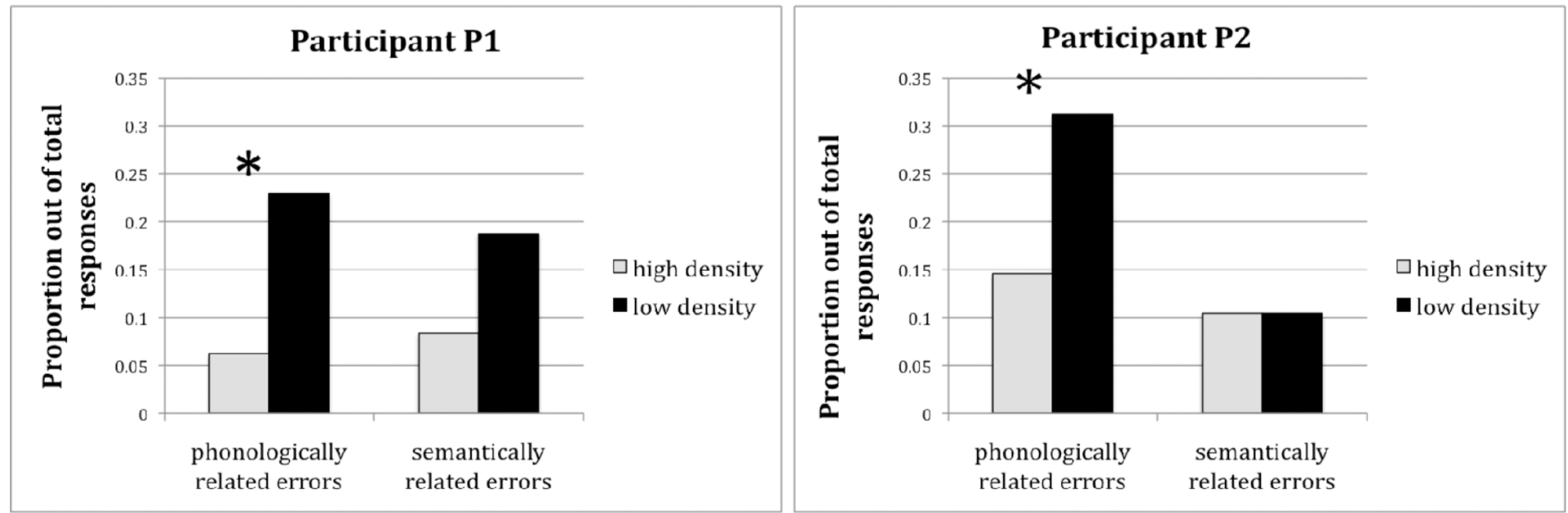

Figure 2.

Proportion of phonologically related errors and semantically related errors as a function of density in Experiment 1. 


\section{Participant P3}

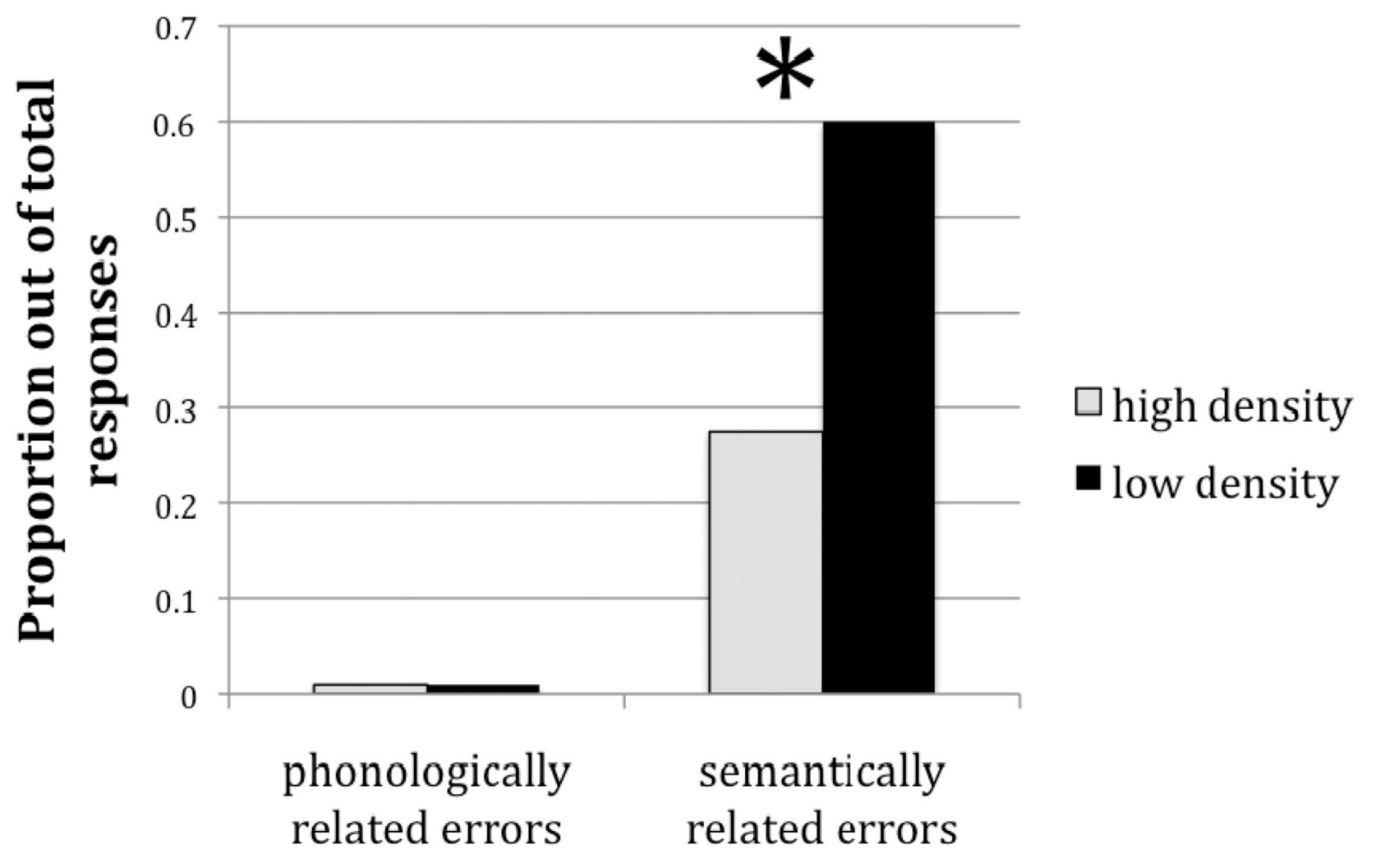

Figure 3.

Proportion of phonologically related errors and semantically related errors as a function of density in Experiment 2. 


\section{Participant P3}

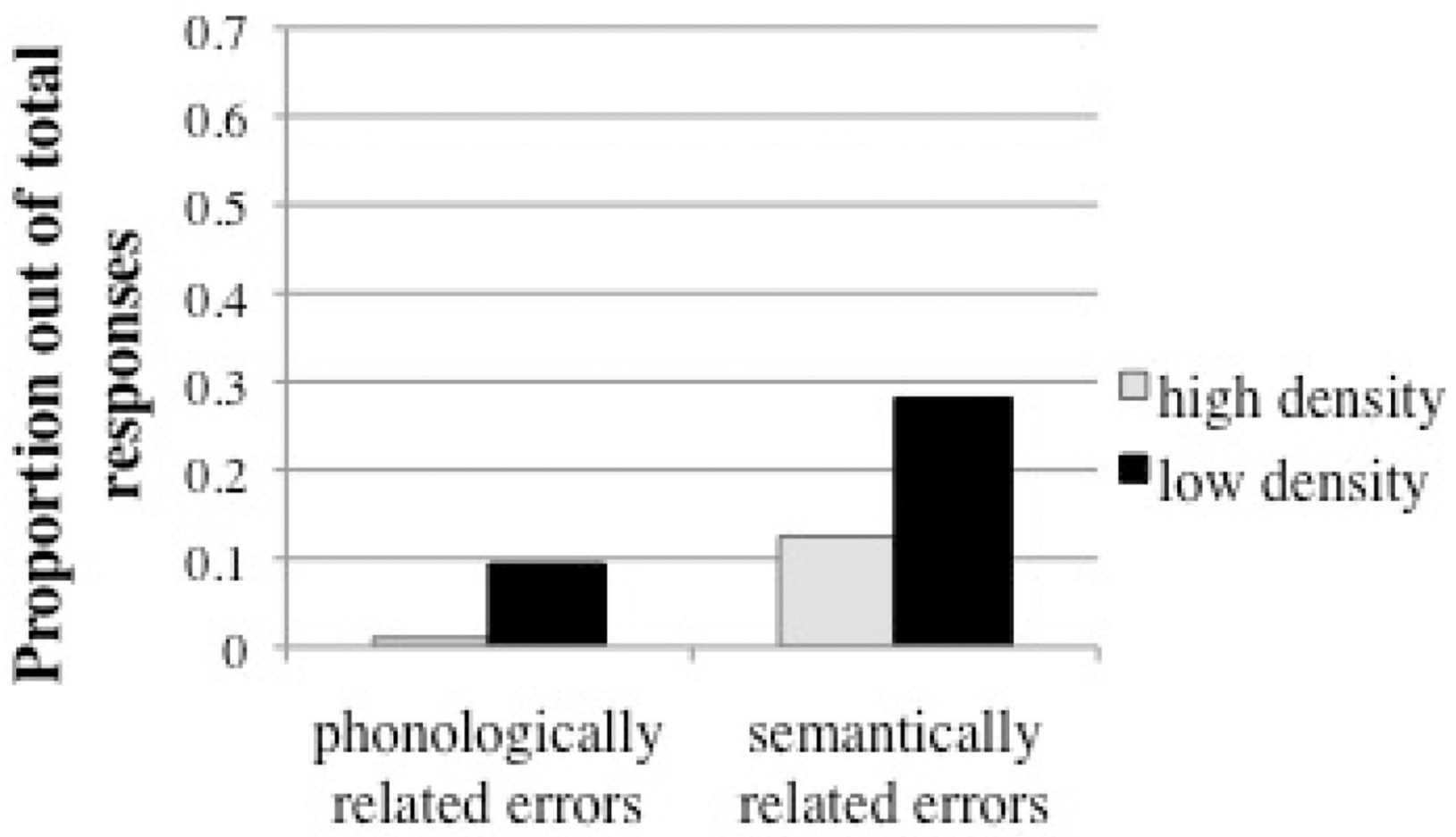

Figure 4.

Proportion of phonologically related errors and semantically related errors as a function of density in Experiment 3. 


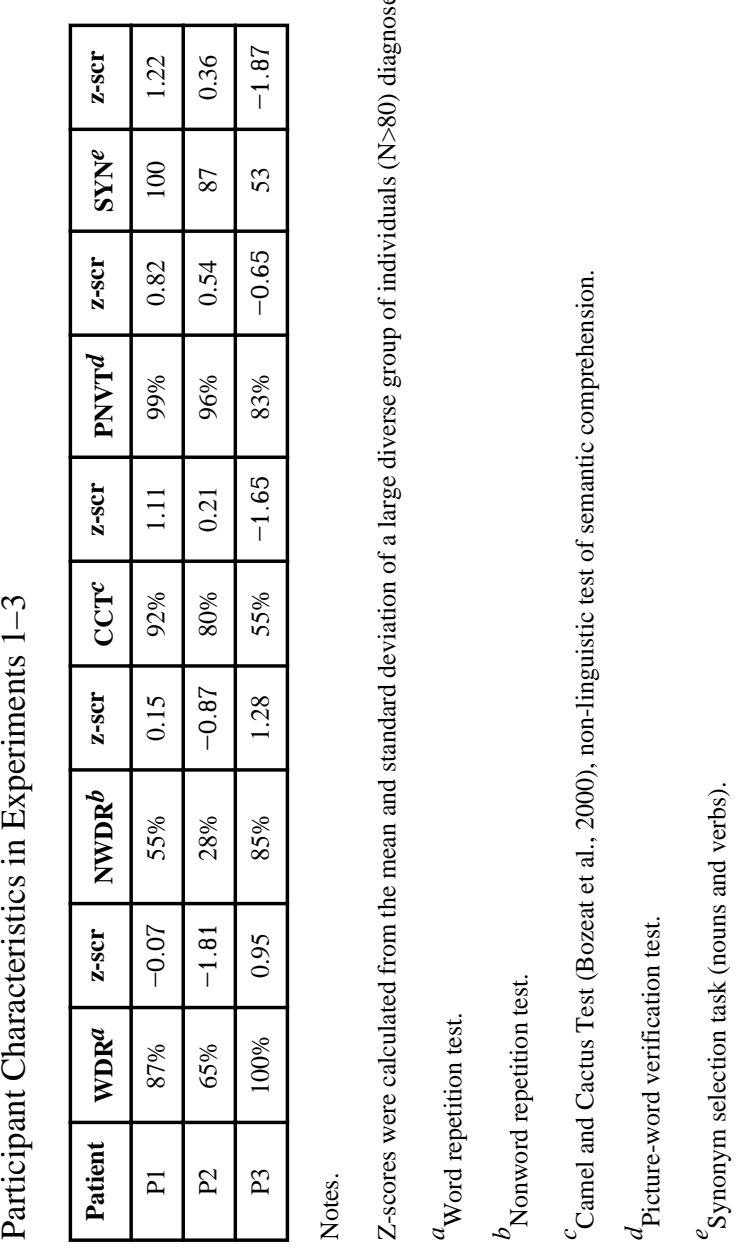




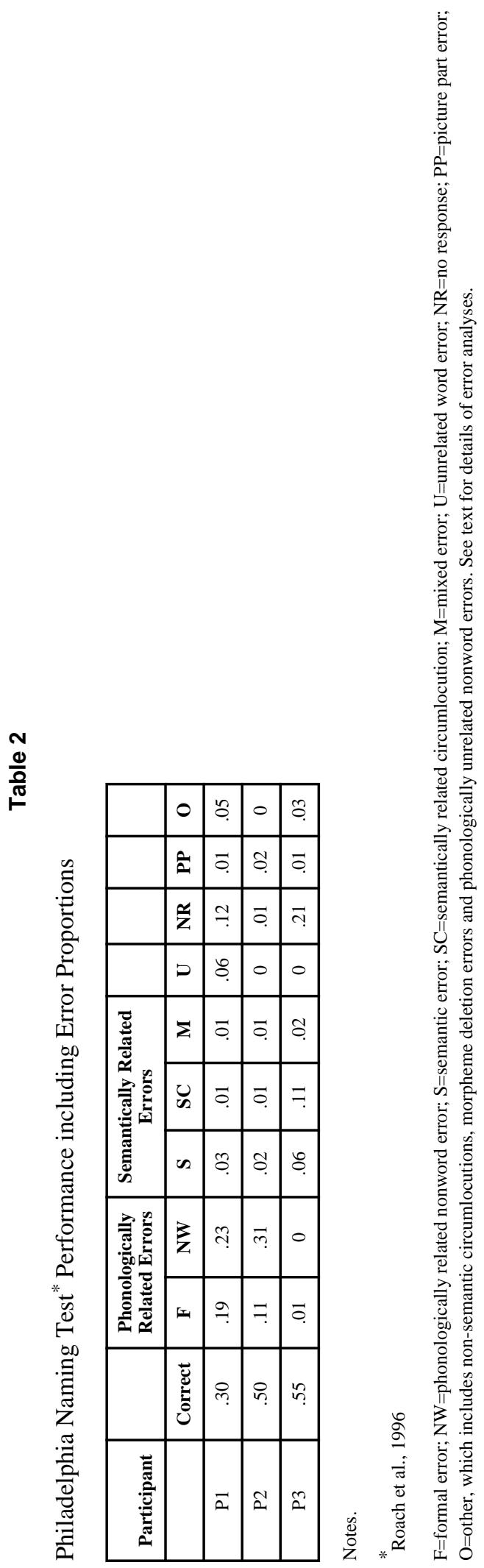

Cogn Neuropsychol. Author manuscript; available in PMC 2011 July 8. 
Table 3

Lexical Characteristics of Materials in Experiment 1

\begin{tabular}{|l|c|c|c|c|}
\hline & $\begin{array}{c}\text { High density } \\
\text { (average) }\end{array}$ & $\begin{array}{c}\text { Low density } \\
\text { (average) }\end{array}$ & $\boldsymbol{t}$-value ${ }^{*}(\boldsymbol{d f = 4 6 )}$ & $\boldsymbol{p}$-value \\
\hline Phonological density & 23.04 & 10.12 & 8.65 & .000 \\
\hline Number of phonemes & 3.12 & 3.88 & 4.84 & .000 \\
\hline Phonotactic probability & .19 & .18 & 0.27 & .78 \\
\hline Familiarity ${ }^{\dagger}$ & 6.97 & 6.93 & 0.81 & .41 \\
\hline Word frequency (per million) & 15.25 & 11.79 & 1.05 & .29 \\
\hline Neighborhood frequency & 162.88 & 69.71 & 2.07 & .04 \\
\hline Presence (=1)/Absence (=0) of higher freq neighbors & 1.00 & .96 & 1.00 & .32 \\
\hline Imageability $^{\dagger}$ & 6.24 & 5.89 & 1.59 & .11 \\
\hline Concreteness ${ }^{\dagger}$ & 5.69 & 5.66 & 0.16 & .86 \\
\hline Age of acquisition ${ }^{\dagger}$ & 2.65 & 3.13 & 3.02 & .004 \\
\hline Proportion name agreement & .96 & .88 & 1.68 & .09 \\
\hline
\end{tabular}

${ }^{\dagger}$ Seven-point scale.

* Absolute value, two-tailed. 
Table 5

Lexical Characteristics of Materials in Experiment 2

\begin{tabular}{|l|c|c|c|c|}
\hline & $\begin{array}{c}\text { High density } \\
\text { (average) }\end{array}$ & $\begin{array}{c}\text { Low density } \\
\text { (average) }\end{array}$ & $\boldsymbol{t}$-value ${ }^{*}(\boldsymbol{d f}=\mathbf{3 8})$ & $\boldsymbol{p}$-value \\
\hline Phonological density & 21.45 & 10.25 & 7.14 & .000 \\
\hline Number of phonemes & 3.20 & 3.80 & 3.62 & .001 \\
\hline Phonotactic probability & .18 & .18 & 0.20 & .83 \\
\hline Familiarity ${ }^{\dagger}$ & 6.96 & 6.93 & 0.55 & .58 \\
\hline Word frequency (per million) & 17.40 & 12.20 & 1.38 & .17 \\
\hline Neighborhood frequency & 155.64 & 71.83 & 1.57 & .12 \\
\hline Presence (=1)/Absence (=0) of higher freq neighbors & 1.00 & .95 & 1.00 & .32 \\
\hline Imageability $^{\dagger}$ & 6.32 & 6.11 & 1.29 & .20 \\
\hline Concreteness ${ }^{\dagger}$ & 5.93 & 5.83 & 0.64 & .52 \\
\hline Age of acquisition ${ }^{\dagger}$ & 2.62 & 2.91 & 1.93 & .06 \\
\hline Proportion name agreement & .96 & .92 & 0.86 & .39 \\
\hline
\end{tabular}

${ }^{\dagger}$ Seven-point scale.

* Absolute value, two-tailed. 


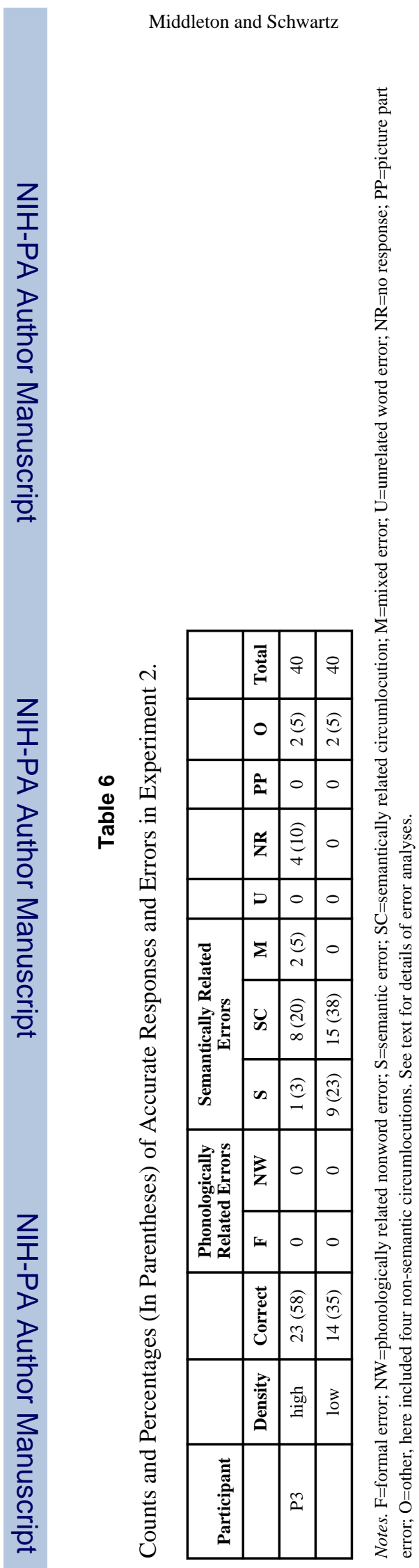

Page 34

Cogn Neuropsychol. Author manuscript; available in PMC 2011 July 8. 
Table 7

Lexical Characteristics of Materials in Experiment 3

\begin{tabular}{|l|c|c|c|c|}
\hline & $\begin{array}{c}\text { High density } \\
\text { (average) }\end{array}$ & $\begin{array}{c}\text { Low density } \\
\text { (average) }\end{array}$ & $\boldsymbol{t}$-value $(\boldsymbol{d} f=\mathbf{3 0})$ & $\boldsymbol{p}$-value \\
\hline Phonological density & 24.88 & 14.31 & 4.88 & .000 \\
\hline Number of phonemes & 3.06 & 3.31 & 1.85 & .07 \\
\hline Phonotactic probability & .17 & .18 & .42 & .67 \\
\hline Familiarity ${ }^{\dagger}$ & 6.97 & 6.96 & .19 & .84 \\
\hline Word frequency (per million) & 81.06 & 47.50 & .87 & .39 \\
\hline Neighborhood frequency & 190.72 & 251.91 & .36 & .72 \\
\hline Presence (=1)/Absence (=0) of higher freq neighbors & .94 & .94 & .00 & 1.00 \\
\hline Imageability $^{\dagger}$ & 6.44 & 6.39 & .34 & .73 \\
\hline Concreteness ${ }^{\dagger}$ & 5.97 & 6.07 & .80 & .42 \\
\hline Age of acquisition ${ }^{\dagger}$ & 2.47 & 2.66 & 1.02 & .31 \\
\hline Proportion name agreement & .98 & .99 & 1.05 & .30 \\
\hline
\end{tabular}

${ }^{\dagger}$ Seven-point scale.

* Absolute value, two-tailed. 


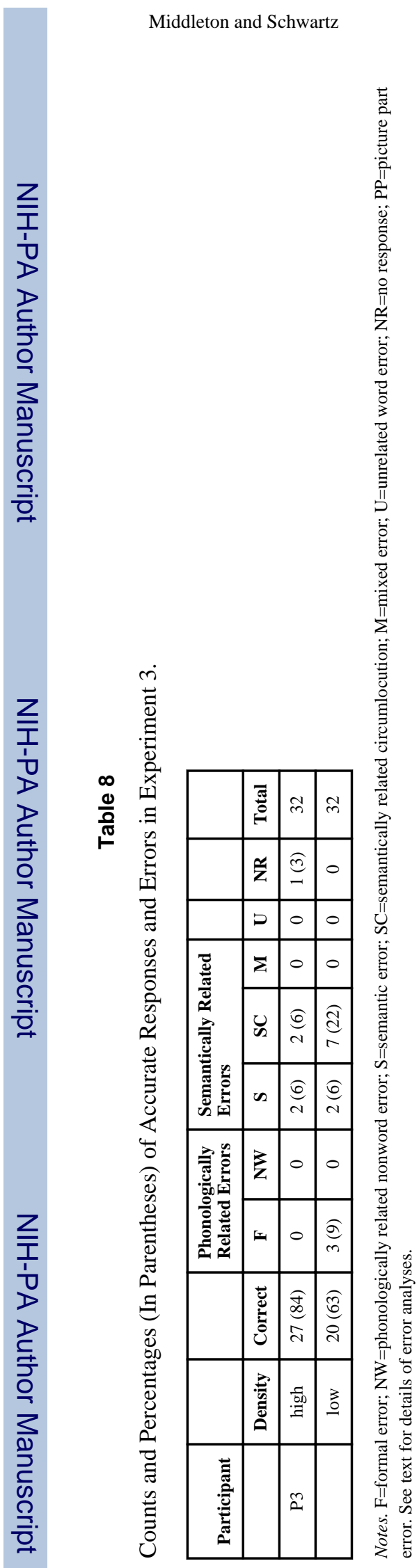

Page 36

Cogn Neuropsychol. Author manuscript; available in PMC 2011 July 8. 